\title{
Low-Temperature CO Oxidation Catalyzed by Free Palladium Clusters: Similarities and Differences to Pd Surfaces and Supported Particles
}

\author{
Sandra M. Lang, ${ }^{\dagger}$ Irene Fleischer, ${ }^{\dagger}$ Thorsten M. Bernhardt, ${ }^{*}{ }^{\dagger}$ Robert N. Barnett, ${ }^{\ddagger}$ and Uzi Landman ${ }^{*}, \ddagger$ \\ ${ }^{\dagger}$ Institute of Surface Chemistry and Catalysis, University of Ulm, Albert-Einstein-Allee 47, 89069 Ulm, Germany \\ ${ }^{\ddagger}$ School of Physics, Georgia Institute of Technology, Atlanta, Georgia 30332-0430, United States
}

Supporting Information

\begin{abstract}
The catalytic low-temperature oxidation of $\mathrm{CO}$ to $\mathrm{CO}_{2}$ with molecular oxygen is of particular industrial and ecological interest. Gas-phase reaction kinetics measurements in conjunction with first-principles calculations provide comprehensive insight into the mechanisms and energetics of the low-temperature $\mathrm{CO}$ combustion reaction catalyzed by small free palladium clusters $\mathrm{Pd}_{x}^{+}(x=2-7)$. Similar to the cases of extended palladium single crystals and supported nanoparticles, the catalytic activity of the free palladium clusters was found to be largely determined by the fast adsorption and dissociation of molecular oxygen and the binding strength of carbon monoxide. In particular, $\mathrm{Pd}_{4}^{+}, \mathrm{Pd}_{5}{ }^{+}$, and $\mathrm{Pd}_{6}{ }^{+}$were found to catalyze the oxidation of $\mathrm{CO}$ at room

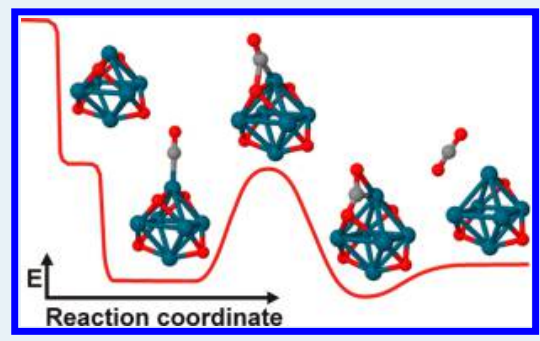
temperature, with $\mathrm{Pd}_{6}{ }^{+}$being most active. Detailed mechanistic investigations of the $\mathrm{CO}$ oxidation reaction catalyzed by $\mathrm{Pd}_{6}^{+}$ reveal a Langmuir-Hinshelwood reaction mechanism, similar to that found earlier for $\mathrm{CO}$ oxidation on palladium single crystals, with comparable energetics. The main difference, however, between the cases of small clusters and extended surfaces arises from a considerably reduced bonding of $\mathrm{CO}$ to the $\mathrm{Pd}_{6}{ }^{+}$cluster compared to the adsorption strength on the $\mathrm{Pd}(111)$ surface, as well as in comparison with the other investigated clusters. This lower $\mathrm{CO}$ binding energy prevents $\mathrm{CO}$ poisoning at, and below, room temperature, and enables effective low-temperature $\mathrm{CO}$ oxidation. Consequently, this study shows that free clusters can serve as model systems for mechanistic studies of catalytic reactions at the molecular level, in addition to opening new ways for the rational design of effective low-temperature $\mathrm{CO}$ oxidation catalysts through tunability of the reaction parameters by changing the number of constituent atoms.
\end{abstract}

KEYWORDS: gas-phase reaction, catalysis, CO oxidation, palladium clusters, density functional theory

\section{INTRODUCTION}

Palladium is one of the most widely employed materials for heterogeneous oxidation catalysts. The particular industrial and scientific interest in palladium originates from its ability to catalyze the $\mathrm{CO}$ combustion reaction and its resulting technological and environmental relevance for the automotive catalytic converter. ${ }^{1}$ However, the main problem of today's three-way catalytic converters is the rather high operation temperature of at least $570 \mathrm{~K}$, inhibiting the conversion of pollutants in the start-up period. ${ }^{2}$ For the targeted development and optimization of new low-temperature catalysts, a molecular level understanding of the energetics and kinetics of the elementary processes involved in the overall catalytic $\mathrm{CO}$ oxidation reaction is of essential importance.

Industrial heterogeneous catalysts usually represent extremely complex systems composed of small metal particles dispersed on porous materials, which inhibits the detailed investigation of principal parameters and elementary reaction mechanisms. Consequently, to gain basic insight into the chemical properties and catalytic activity of palladium, numerous studies on simplified model systems like extended Pd single crystal surfaces, supported nanoparticles, small supported clusters, and also small gas phase clusters have been performed during the past several decades. Although these models represent systems of varying complexity, and although the experiments were performed over a large range of experimental conditions, these methods turned out to be highly complementary and already revealed a number of pertinent details about the catalytic $\mathrm{CO}$ combustion reaction. To put our paper in context and to provide a framework for the discussion of our gas-phase cluster experiments and firstprinciples theoretical simulations, we first overview certain pertinent findings from earlier studies.

1.A. Pd Single Crystals. Ordered extended metal surfaces are structurally well-characterized, and their properties have been well-studied for the past several decades, thus making them well-suited as a model system for the investigation of heterogeneous catalysis. Indeed, more than three decades ago, Ertl and co-workers showed that the oxidation reaction of $\mathrm{CO}$ proceeds on palladium single crystals via a complex reaction mechanism of the Langmuir-Hinshelwood (LH) type. These authors have identified two key factors which determine the

\footnotetext{
Received: June 10, 2014

Revised: January 22, 2015

Published: March 11, 2015
} 
efficiency of this reaction: ${ }^{3}$ (1) the dissociative chemisorption of oxygen on the catalyst surface and (2) the adsorption strength of carbon monoxide. ${ }^{3 \mathrm{~b}}$ Once $\mathrm{CO}$ and dissociated oxygen are simultaneously formed on the palladium surface, the formation and desorption of $\mathrm{CO}_{2}$ was observed to be fast, ${ }^{3 \mathrm{a}, 4}$ and the $\mathrm{LH}$ activation barriers for the total $\mathrm{CO}$ combustion reaction were experimentally determined by two different groups to amount to $105 \pm 8 \mathrm{~kJ} \mathrm{~mol}^{-13 \mathrm{~b}}$ and $118 \pm 1 \mathrm{~kJ}$ $\mathrm{mol}^{-1},{ }^{4}$ respectively, at low $\mathrm{CO}$ coverages $(T>500 \mathrm{~K})$ and to $59 \pm 8 \mathrm{~kJ} \mathrm{~mol}^{-13 \mathrm{~b}}$ at moderate $\mathrm{CO}$ coverages $(T<500 \mathrm{~K})$.

On Pd single crystals, $\mathrm{O}_{2}$ adsorption and dissociation proceed essentially without an activation barrier ${ }^{3 \mathrm{~b}}$ and were observed to occur even at temperatures as low as $200 \mathrm{~K}^{5}$ In contrast, $\mathrm{CO}$ adsorbs nondissociatively with binding energies ranging between $129 \mathrm{~kJ} \mathrm{~mol}^{-1}$ and $185 \mathrm{~kJ} \mathrm{~mol}^{-1}$ at low CO coverages, depending on the $\mathrm{CO}$ coverage and the applied analytical method. ${ }^{4,6}$

These rather high $\mathrm{CO}$ adsorption energies cause a fast covering (saturation) of the catalyst surface with $\mathrm{CO}$, which inhibits $\mathrm{O}_{2}$ coadsorption at low temperatures and leads to catalyst poisoning. As a result, a reaction temperature of at least around $450 \mathrm{~K}$ is required to enable $\mathrm{CO}_{2}$ formation. ${ }^{1,3 \mathrm{~b}}$ Consequently, the rate-limiting step of the reaction is believed to be the desorption of $\mathrm{CO}$ molecules to liberate $\mathrm{O}_{2}$ adsorption sites, which in turn determines the rate of oxygen adsorption. ${ }^{4}$ However, due to a rather complicated mutual interaction of the reactants as a function of the surface coverage and the temperature, it was not possible to formulate simple kinetic schemes for the reaction, valid over the entire range of accessible temperature and pressure conditions. $3 \mathrm{~b}, 7$

The formation of oxides on metal surfaces has received much attention over the years, with a surge in surface science research efforts in this area taking place for a little over a decade now. In addition to the fundamental importance of understanding oxidation processes that are often associated with corrosion, metal surface oxidation, for selected conditions, can lead to the growth of oxide layers, which can be employed as protective coating against corrosion, as insulating layers in microelectronic devices, and, most pertinent for this paper, as catalytic substrates even where the catalytic behavior has been attributed in the past to the bare metal surface. ${ }^{8}$ For late transition metals and noble metals (e.g., Pd and $\mathrm{Ag}$ ), it has been demonstrated that oxidation proceeds through formation of ultrathin (down to monolayer thickness) thermodynamically stable oxide layers that may be of high structural complexity ${ }^{9}$ and may exhibit structural properties unrelated to the metal structure or to the bulk oxides; ${ }^{9}$ see, in particular, the complex structure of the "surface oxide" formed on $\mathrm{Pd}(111)$ from the $\mathrm{Pd}_{5} \mathrm{O}_{4}$ adsorbate unit cell, as found from combined scanning tunneling microscopy, surface X-ray diffraction, high-resolution core level spectroscopy, and density functional calculations. ${ }^{9 \mathrm{~b}}$ It has been concluded ${ }^{\text {b }}$ that from consideration of both the structural and energetic aspects of the system under study, the ultrathin surface oxide (of subnanometer thickness, with the core level energies calculated for the Pd layer directly below the surface oxide layer being almost exactly the same as for bulk $\mathrm{Pd}$ ) is an intermediate phase between an oxygen overlayer (that is surface-adsorbed oxygen) and a bulk oxide, and as such, it could have interesting consequences for heterogeneous catalysis. It is pertinent to remark ${ }^{9 b}$ that the above findings contrast earlier views where it was assumed that oxygen on metal surfaces forms either overlayers, sometimes causing simple rearrangements of the metal atoms such as vacancies ${ }^{10}$ or additional metal atoms ${ }^{11}$ at lattice sites, or causes the formation of oxides, which were believed to be identical or closely related to the corresponding bulk oxides; a larger variety of structures have been observed in oxides of one metal grown on a different metal (see, e.g., ref 12 and references therein).

Although the formation of different oxygen species is assumed to strongly influence the catalytic activity, the detailed role of different oxygen species remains largely elusive. Systematic studies ${ }^{8 \mathrm{~b}}$ identified dissociatively adsorbed surface oxygen, $\mathrm{O}(\mathrm{ad})$, as the most reactive species on both $\mathrm{Pd}(100)$ and $\operatorname{Pd}(111)$ surfaces, followed by the reactivity of the aforementioned $\mathrm{Pd}_{5} \mathrm{O}_{4}$ surface oxide ${ }^{9 \mathrm{~b}}$ on $\mathrm{Pd}(111)$, which reacted with $\mathrm{CO}$ at a higher temperature $(330 \mathrm{~K}$ compared to $223 \mathrm{~K}$ for $\mathrm{CO}$ oxidation on $\mathrm{O}(\mathrm{ad}) / \mathrm{Pd}(111)$, with the catalytic activities of the two systems becoming comparable at $400 \mathrm{~K}$ ). On the other hand, continuous (substoichiometric) $\mathrm{PdO}_{x}$ layers were found to be much less reactive toward $\mathrm{CO}$, and $\mathrm{PdO}$ did not react with $\mathrm{CO}$ below $493 \mathrm{~K}$ even around $10 \mathrm{mbar}$ (probably due to the lack of adsorption sites for $\mathrm{CO}$ on bulk $\mathrm{PdO}$ as compared to the $\mathrm{Pd}_{5} \mathrm{O}_{4}$ surface oxide). ${ }^{8 \mathrm{~b}}$

1.B. Supported Pd Nanoparticles. Despite the important fundamental knowledge gained in experimental studies on $\mathrm{Pd}$ single crystals, these model systems cannot account for all characteristics of technical catalysts. In particular, the finite size of the catalytically active metal particles as well as the interaction between the metal particles and the support material requires more complex model systems which can be found (e.g., in palladium nanoparticles supported on welldefined single crystalline (thin film) oxide surfaces). ${ }^{13}$ One particularly important issue in these systems is the determination of particle size effects which, however, turned out to be difficult, and thus, it remained for a rather long time unclear to what an extent size effects control the kinetics and energetics of the $\mathrm{CO}$ combustion reaction (see ref $13 \mathrm{a}$ and references therein).

Palladium nanoparticles were found to form a variety of oxygen species, like interfacial, surface, subsurface, and bulk oxygen or PdO-like oxide shells, depending on the applied reaction conditions and also on particle size. ${ }^{14}$ Similar to extended $\mathrm{Pd}$ single-crystal surfaces, dissociative $\mathrm{O}_{2}$ adsorption on Pd nanoparticles was observed at temperatures as low as 200 $\mathrm{K}^{14 \mathrm{a}}$ Hence, $\mathrm{O}_{2}$ adsorption and dissociation occurs already well below room temperature also on Pd particles and should not be the rate-determining reaction step for low-temperature $\mathrm{CO}$ oxidation. However, only oxygen atoms chemisorbed on the metallic Pd nanoparticles have so far been identified to be directly involved in the $\mathrm{CO}$ oxidation reaction, whereas oxide layers formed at the metal/support interface of, for example, $\mathrm{Fe}_{3} \mathrm{O}_{4}$-supported nanoparticles, were found to only serve as an oxygen reservoir. ${ }^{14 \mathrm{~d}}$

With respect to the binding energy of $\mathrm{CO}$ on palladium nanoparticles, temperature-programmed desorption and modulated molecular beam studies revealed no clear particle-sizedependent trend. For example, Henry and co-workers observed an increase in the $\mathrm{CO}$ binding energy for particles smaller than $5 \mathrm{~nm}$ supported on $\mathrm{MgO}(100)$ (increase of more than $33.5 \mathrm{~kJ}$ $\mathrm{mol}^{-1}$ for a $2 \mathrm{~nm}$ particle compared to a Pd single crystal). ${ }^{6 f, 15}$ In contrast, Stará et al. detected a decrease of about $11 \mathrm{~kJ} \mathrm{~mol}^{-1}$ for a $2.5 \mathrm{~nm}$ particle on $\mathrm{Al}_{2} \mathrm{O}_{3}$ compared to $\mathrm{Pd}(111) .{ }^{16}$ Direct calorimetric measurements of the $\mathrm{CO}$ heat of adsorption demonstrated a reduction by up to $42 \mathrm{~kJ} \mathrm{~mol}^{-1}$ for a $1.8 \mathrm{~nm}$ particle on a well-ordered $\mathrm{Fe}_{3} \mathrm{O}_{4} / \mathrm{Pt}(111)$ film as compared to $\mathrm{Pd}(111) .{ }^{17}$ Furthermore, $\mathrm{CO}$ was found to dissociate on 
palladium nanoparticles (see ref $13 \mathrm{a}$ and references therein). Most recently, Henry and co-workers reported a study of CO adsorption on regular, almost monodisperse arrays of $\mathrm{Pd}$ particles on nanostructured alumina ultrathin films. This investigation revealed a highly discontinuous evolution of the $\mathrm{CO}$ adsorption energy with particle size in the range between 1 and $2 \mathrm{~nm}$ of the particles' diameters, with values as low as $30 \mathrm{~kJ}$ $\mathrm{mol}^{-1} \cdot 18$

Particle size effects appear to be currently rather ambiguous not only with respect to the interaction of $\mathrm{O}_{2}$ and $\mathrm{CO}$ with palladium nanoparticles but also related to the complete catalytic $\mathrm{CO}$ oxidation reaction. In agreement with studies on Pd single crystals, the reaction was found to proceed via a Langmuir-Hinshelwood mechanism. ${ }^{14 \mathrm{a}, \mathrm{d}, 19}$ For particles with an average $5.5 \mathrm{~nm}$ diameter supported on $\mathrm{Al}_{2} \mathrm{O}_{3}$ the Langmuir-Hinshelwood activation energy was experimentally determined to be $57 \pm 6 \mathrm{~kJ} \mathrm{~mol}^{-1}$ at high $\mathrm{CO}$ and low oxygen coverage and $62 \pm 8 \mathrm{~kJ} \mathrm{~mol}^{-1}$ at low $\mathrm{CO}$ and high oxygen coverage, ${ }^{14 a}$ which is in excellent agreement with the activation barrier determined for $\mathrm{Pd}(111)$ in the lower-temperature regime $(<500 \mathrm{~K})$, that is, $59 \pm 8 \mathrm{~kJ} \mathrm{~mol}^{-1}$. $^{3 \mathrm{~b}}$ In contrast, in a different study, a strongly decreasing activation energy with decreasing particle size was observed, that is, 45-64 $\mathrm{kJ} \mathrm{mol}^{-1}$ for $\mathrm{Pd}(111), 32-45 \mathrm{~kJ} \mathrm{~mol}^{-1}$ for $27 \mathrm{~nm} \mathrm{Pd} / \mathrm{Al}_{2} \mathrm{O}_{3}$, and $19-20$ $\mathrm{kJ} \mathrm{mol}{ }^{-1}$ for $2.5 \mathrm{~nm} \mathrm{Pd} / \mathrm{Al}_{2} \mathrm{O}_{3}$. This indicates an increased catalytic activity for smaller particles. ${ }^{19}$

In summary, the overall features of the catalytic $\mathrm{CO}$ combustion reaction mediated by supported $\mathrm{Pd}$ nanoparticles are similar to those observed on extended Pd single crystals: (1) The reaction proceeds via a Langmuir-Hinshelwood reaction mechanism; (2) Molecular oxygen adsorbs dissociatively on Pd nanoparticles even at temperatures below $300 \mathrm{~K}$; (3) $\mathrm{CO}$ adsorption energies are comparable to those of $\mathrm{Pd}$ surfaces over a wide particle size range resulting in required reaction temperatures well above room temperature to avoid catalyst poisoning. Only small particles with diameters of a few nanometers seem to exhibit size effects.

As an explanation for these surprising observations in the very small size range, formation of subsurface oxygen as the reactive oxidant species on small particles has been inferred. ${ }^{13 a}$ Additionally, it is reasonable to expect that different $\mathrm{CO}$ adsorption sites on defects like corners, edges, and kinks, whose relative abundance increases with decreasing particle size, may contribute to the changed catalytic activity. Furthermore, for supported small particles, ${ }^{13 a}$ precursor state effects (e.g., the capture of molecules first physisorbed on the oxide support) may affect considerably the energetics and kinetics of the overall reaction.

1.C. Small Supported Clusters. As detailed above, experimental studies on supported nanoparticles indicated size effects in the catalytic CO combustion reaction for very small particles of only a few nanometers in size. Even more pronounced size effects can be expected for clusters in the socalled nonscalable size regime ${ }^{20}$ (up to about 100 atoms per cluster) where the particle properties change nonmonotonically with cluster size. However, studies of such model systems are more scarce.

Magnesia-supported palladium atoms and clusters, $\mathrm{Pd}_{x} /$ $\mathrm{MgO} / \mathrm{Mo}(100)$, comprising up to 30 atoms were observed to catalyze the $\mathrm{CO}$ oxidation reaction already at $300 \mathrm{~K}$ and below. ${ }^{21}$ This finding was interpreted by a reduced $\mathrm{CO}$ binding energy on these small clusters compared to single crystals resulting in the availability of unoccupied $\mathrm{O}_{2}$ adsorption sites and thus enabling $\mathrm{CO}$ oxidation already at lower temperatures. Most interestingly, preadsorbed $\mathrm{CO}$ was even found to promote oxygen adsorption and dissociation in the temperature range of $300-420 \mathrm{~K}$ instead of blocking possible oxygen adsorption sites as on single crystals. ${ }^{2 \mathrm{~b}} \mathrm{~A}$ cooperative Langmuir-Hinshelwood mechanism was proposed to describe the observed reaction behavior, and these results revealed for the first time details of the coadsorption effects between $\mathrm{O}_{2}$ and $\mathrm{CO}^{21 \mathrm{~b}}$ Furthermore, comprehensive combined experimental and theoretical studies ${ }^{21 d}$ indicated a competition between a Mars-van Krevelen ${ }^{22}$ and a Langmuir-Hinshelwood type reaction mechanism for the $\mathrm{CO}$ oxidation catalyzed by $\mathrm{Pd}_{30} /$ $\mathrm{MgO}$ depending on the reaction temperature; a similar result was found ${ }^{21 \mathrm{c}}$ also for $\mathrm{Pd}_{13} / \mathrm{MgO}$. Concerning the oxidation state of the clusters, the low-symmetry palladium oxide $\mathrm{Pd}_{13} \mathrm{O}_{6} / \mathrm{MgO}$ was found ${ }^{21 \mathrm{c}}$ to exhibit smaller activation barriers for $\mathrm{CO}$ oxidation compared to the highly symmetric $\mathrm{Pd}_{13} \mathrm{O}_{4} /$ $\mathrm{MgO}^{21 \mathrm{c}}$

In a different experiment, strong size effects in the oxidation of $\mathrm{CO}$ mediated by $\mathrm{Pd}_{x} / \mathrm{TiO}_{2}(110)(x=1-25)$ have been found to correlate with the oxygen activation efficiency, which in turn was attributed to variations in the cluster electronic structure. $^{23}$ It was suggested that the formation of reactive oxygen is an activated process for all cluster sizes and that this represents the limiting factor that largely determines the sizedependent activity. However, XPS studies have shown that small clusters $\operatorname{Pd}_{x}(x=1,7,10,13)$ supported on alumina are efficiently oxidized by exposure to $\mathrm{O}_{2}$ already at $100 \mathrm{~K}$ with no or little activation barrier, whereas no oxidation was found for $\mathrm{Pd}_{4}{ }^{24}$ Subsequent theoretical studies attributed this behavior to an anomalously small charge donation from $\mathrm{Pd}_{4}$ to the adsorbed $\mathrm{O}_{2}$ due to an enhanced stability of $\mathrm{Pd}_{4}{ }^{25}$

Density functional theory studies on small magnesiasupported palladium clusters revealed an unexpected low dissociation barrier $\left(48 \mathrm{~kJ} \mathrm{~mol}^{-1}\right)$ for $\mathrm{O}_{2}$ on $\mathrm{Pd}_{9} / \mathrm{MgO}$, implying that the $\mathrm{O}_{2}$ dissociation reaction should be observable well below room temperature on this cluster. ${ }^{26}$ However, a rather strong adsorption of $\mathrm{CO}$ on $\mathrm{Pd}_{9} / \mathrm{MgO}$ was found to inhibit subsequent $\mathrm{O}_{2}$ dissociation resulting in the poisoning of the catalyst. Hence, these results indicate that small Pd clusters will catalyze $\mathrm{CO}$ oxidation best under $\mathrm{O}_{2}$-rich conditions where preformation of crystalline nano-oxide clusters $\mathrm{Pd}_{x} \mathrm{O}_{y}$ is possible. Under these reaction conditions $\mathrm{CO}_{2}$ formation and adsorption (release) is predicted to involve activation barriers of $60-100 \mathrm{~kJ} \mathrm{~mol}^{-1}$.

Although the number of studies on small supported clusters is rather limited, there are clear indications for the appearance of nontrivial size effects. In particular, cooperative effects on such small particles may considerably reduce the temperature needed to avoid catalyst poisoning and enable effective $\mathrm{CO}$ oxidation. Thus, more detailed studies on cluster-size-specific oxygen activation, $\mathrm{CO}$ adsorption, as well as $\mathrm{CO}_{2}$ formation and desorption processes are desirable.

1.D. Free Clusters. Small clusters in the gas phase may represent model systems for detailed studies on a (rigorous) molecular level. ${ }^{27}$ Despite the fact that free clusters cannot account for a number of complex processes occurring in catalytic processes on solid surfaces (particularly involving supported catalytic particles), they can be employed to model the catalytically active centers, ${ }^{28}$ that is, the locations where the actual chemical transformations involved in the catalytic reactions take place. Such active sites are usually characterized by a spatial extension on the subnanometer scale and may 
involve defect sites, undercoordinated atoms, or unsaturated bonds, which may be appropriately modeled with the use of small clusters. ${ }^{29}$ Hence, the gas phase study of free palladium clusters provides an attractive complementary approach to the other model systems discussed above.

Both anionic ${ }^{30}$ and neutral ${ }^{31}$ palladium clusters have been found to readily react with molecular oxygen without significant cluster size dependence. Insights into the $\mathrm{O}_{2}$ binding to the $\mathrm{Pd}$ atom has been gained by ultraviolet photoelectron spectroscopy of $\mathrm{PdO}_{2}{ }^{-}$, which revealed the dissociation of the oxygen molecule resulting in a linear $\mathrm{O}-\mathrm{Pd}-\mathrm{O}$ geometry in agreement with previous studies. ${ }^{32}$ However, the structure of the larger complexes $\mathrm{Pd}_{x} \mathrm{O}_{2}^{-}(x=2-7)$ could not be clearly assigned. ${ }^{30 \mathrm{~b}}$ Theoretical studies have mainly been performed on selected neutral clusters so far. ${ }^{33}$ Detailed investigations of $\operatorname{Pd}_{x}(x=2-$ 4) employing spin density functional theory demonstrated the dissociative adsorption of a first oxygen molecule leading to oxygen atoms sitting on $\mathrm{Pd}$ bridge sites. ${ }^{33 \mathrm{a}}$ In agreement with this observation, $\mathrm{Pd}_{4} \mathrm{O}_{2}{ }^{\mp}$ complexes containing activated or dissociated oxygen have been theoretically found to be energetically more favorable than complexes containing molecular oxygen. ${ }^{33 \mathrm{~d}}$

With respect to cationic palladium clusters, energetic collisions of $\mathrm{Pd}^{+}$ions with molecular oxygen have been investigated previously. ${ }^{34}$ However, only recently, have the details of the cluster-size- and temperature-dependent bonding and activation of molecular oxygen by palladium cluster cations $\operatorname{Pd}_{x}^{+}(x=2-7)$ been reported by the present authors. ${ }^{35}$ The results reveal the preferred formation of tetroxide product complexes, $\mathrm{Pd}_{x} \mathrm{O}_{4}^{+}$for all investigated cluster sizes, although a strong cluster-size-dependent reactivity toward a first $\mathrm{O}_{2}$ molecule has been detected. Concomitant theoretical simulations indicated that these palladium tetroxide complexes contain dissociatively chemisorbed oxygen over a large part of the investigated temperature range $(100-300 \mathrm{~K})$, whereas additional molecularly adsorbed $\mathrm{O}_{2}$ was only found at cryogenic temperatures. $^{35,36}$

In contrast to the reaction with $\mathrm{O}_{2}$, small anionic ${ }^{37}$ and neutral ${ }^{38}$ palladium clusters show a more pronounced cluster size specific behavior in the reaction with $\mathrm{CO}$. For cationic $\mathrm{Pd}_{x}^{+}$, an enhanced reactivity toward $\mathrm{CO}$ with increasing cluster size has recently been observed over a wide temperature range between 100 and $300 \mathrm{~K}^{39}$ Most interestingly, the binding energies of a first $\mathrm{CO}$ molecule to palladium clusters of all charge states strongly vary with the addition of each $\mathrm{Pd}$ atom. ${ }^{40}$ Finally, infrared spectroscopic studies of $\mathrm{Pd}_{x}(\mathrm{CO})^{ \pm}(x=3-12)$ revealed the molecular adsorption of a first $\mathrm{CO}$ molecule on top, bridge, and hollow sites with varying probabilities. ${ }^{37 \mathrm{c}}$

Although a considerable number of experimental and theoretical contributions investigate the reaction of free (gas phase) palladium clusters with $\mathrm{O}_{2}$ or $\mathrm{CO}$ separately, there are hardly any studies of such clusters addressing the catalytic $\mathrm{CO}$ combustion reaction. Only recently, reactivity studies in an octopole ion trap from this laboratory have revealed the fast formation and desorption of $\mathrm{CO}_{2}$ after the exposure of preoxidized palladium clusters $\mathrm{Pd}_{x} \mathrm{O}^{+}(x=3-5)$ and $\mathrm{Pd}_{x} \mathrm{O}_{2}^{+}$ $(x=4-6)$ to $\mathrm{CO}^{39}$ In contrast, $\mathrm{CO}$ oxidation was less pronounced in the case of $\mathrm{Pd}_{2} \mathrm{O}^{+}, \mathrm{Pd}_{6} \mathrm{O}^{+}$, and $\mathrm{Pd}_{7} \mathrm{O}^{+}$, indicating enhanced activation barriers involved in the $\mathrm{CO}$ oxidation and/ or $\mathrm{CO}_{2}$ desorption process on these particular cluster monooxides. $^{39}$

Using a different approach, which employed guided-ionbeam mass spectrometry in conjunction with density functional theory calculations, the importance of oxygen radical centers for the $\mathrm{CO}$ oxidation capabilities of preoxidized $\mathrm{PdO}_{2}{ }^{+}$and $\mathrm{PdO}_{3}{ }^{+}$ has been investigated. These studies gave experimental evidence for both direct and cooperative $\mathrm{CO}$ oxidation mechanisms. ${ }^{41}$ Finally, the charge-state-dependent interaction of $\mathrm{Pd}_{4} \mathrm{O}_{y}{ }^{ \pm}(y=1,2)$ with $\mathrm{CO}$ was theoretically simulated, predicting an enhanced activity of the cationic and neutral cluster compared to the anionic one. ${ }^{33 \mathrm{~d}}$

So far, investigations of the $\mathrm{CO}$ combustion reaction utilizing free $\mathrm{Pd}$ clusters focused mainly on the formation and desorption of $\mathrm{CO}_{2}$ on preoxidized clusters. Similarly, most studies on single-crystal surfaces as well as on supported nanoparticles and clusters, utilized pulsed methods, where palladium oxide is prepared prior to the reaction with $\mathrm{CO}$. In contrast, in a recent contribution, we reported for the first time on a joined experimental gas phase and first-principles DFT study of the room temperature $\mathrm{CO}$ oxidation reaction catalyzed by $\mathrm{Pd}_{6}{ }^{+}$, where a full thermal catalytic reaction cycle has been revealed. ${ }^{35 a}$ These experiments were performed with massselected $\mathrm{Pd}_{6}^{+}$clusters that were stored in a temperature controlled radio frequency (rf) octopole ion trap where they reacted under multicollision conditions with $\mathrm{O}_{2}$ and $\mathrm{CO}$ (see also Experimental and Computational Methods).

In the work presented here, we have extended the previous room-temperature kinetic investigation and present a full account of the experimental temperature and pressure dependencies. A more comprehensive insight into mechanistic details and the energetics of the catalytic $\mathrm{CO}$ oxidation reaction is gained by theoretical simulations, which allow a direct comparison of the energetics of the gas phase reaction with previous studies that were carried out on extended Pd surfaces and nanoparticles. Furthermore, the investigations have been expanded to include other cluster sizes $\mathrm{Pd}_{x}^{+}(x=2-7)$ as well as the palladium mono-oxides $\mathrm{Pd}_{x} \mathrm{O}^{+}$, in order to gain detailed insight into the role of oxygen adsorption and dissociation as well as the $\mathrm{CO}$ binding strength in the complex $\mathrm{CO}$ oxidation reaction. In particular, similarities and differences to extended $\mathrm{Pd}$ single crystals and supported nanoparticles will be discussed.

\section{EXPERIMENTAL AND COMPUTATIONAL METHODS}

2.A. Experimental Method. Experimental Setup. The gas-phase reactions of small palladium clusters have been studied in an rf octopole ion trap embedded into a low-energy ion beam assembly of quadrupole ion guides and mass spectrometers. The general experimental layout has been described in detail elsewhere ${ }^{42}$ and will only be outlined briefly here (more experimental details can also be found in the Supporting Information).

Palladium clusters $\mathrm{Pd}_{x}^{+}$and their oxides $\mathrm{Pd}_{x} \mathrm{O}^{+}$are generated by simultaneous sputtering of four preoxidized palladium targets with high-energy Xe ion beams, which are produced in a CORDIS (cold reflex discharge ion source). ${ }^{43}$ The formed cluster ion beam is steered into a first helium-filled quadrupole ion guide to collimate and thermalize the hot clusters. Subsequently, cluster ions of the desired size are selected from the beam by means of a mass-selecting quadrupole filter and are transferred via a second quadrupole ion guide into the home-built octopole ion trap. The ion trap is prefilled with about $1 \mathrm{~Pa}$ of helium buffer gas and a mixture of $\mathrm{O}_{2}$ and $\mathrm{CO}$ at variable partial pressure ratios (reactant partial pressure typically $1-20 \%$ of the total pressure). The ion trap is attached to a closed cycle helium cryostat, which, in combination with a resistive heater, allows for temperature adjustment in the range 
between 20 and $300 \mathrm{~K}$. Thermal equilibration of the clusters is achieved within a few milliseconds under our experimental conditions, ${ }^{42}$ whereas the clusters are stored in the ion trap for a considerably longer time, typically between $0.1 \mathrm{~s}$ and several seconds. The $\mathrm{CO}$ oxidation reaction occurs under thermal conditions in the ion trap experiment and thus proceeds on the electronic ground state potential energy surface.

After reaction of the clusters in the ion trap for a chosen time (reaction time $t_{\mathrm{R}}$ ) all ions, intermediates, and final products are extracted, and the ion distribution is analyzed in a second quadrupole mass filter. Kinetic data are obtained by recording the intensity of all ion signals as a function of the reaction time. The normalized kinetic traces are then evaluated by fitting the integrated rate equations of potential reaction mechanisms to the experimental data utilizing the software package "Detmech". ${ }^{44}$ This leads to the determination of the simplest reaction mechanism that best fits the experimental data.

Data Evaluation. To analyze the differences in the catalytic activity of the investigated $\mathrm{Pd}_{x}^{+}$clusters, it is necessary to briefly introduce the reaction models underlying the experimentally determined reactions.

The total pressure inside the ion trap is about $1 \mathrm{~Pa}$, which means that the experiments are performed in the kinetic lowpressure regime. Therefore, the details of each association reaction between a palladium cluster $\mathrm{Pd}_{x}^{+}$and a neutral molecule $\mathrm{L}\left(\mathrm{L}=\mathrm{O}_{2}, \mathrm{CO}\right)$

$$
\mathrm{Pd}_{x}^{+}+\mathrm{L} \rightarrow \mathrm{Pd}_{x} \mathrm{~L}^{+} \quad k_{1}
$$

can be described by the Lindemann energy transfer model for association reactions ( $k_{1}$ is the corresponding rate constant $){ }^{45}$ which is represented by the following elementary reaction steps

$$
\begin{aligned}
& \mathrm{Pd}_{x}^{+}+\mathrm{L} \rightleftarrows\left(\mathrm{Pd}_{x} \mathrm{~L}^{+}\right)^{*} \quad k_{\mathrm{a}}, k_{\mathrm{d}} \\
& \left(\mathrm{Pd}_{x} \mathrm{~L}^{+}\right)^{*}+\mathrm{He} \rightarrow \mathrm{Pd}_{x} \mathrm{~L}^{+}+\mathrm{He}^{*} \quad k_{\mathrm{s}}
\end{aligned}
$$

According to this model, $\mathrm{Pd}_{x}^{+}$reacts with the neutral molecule L (rate constant $k_{\mathrm{a}}$ ) under formation of an energized complex $\left(\mathrm{Pd}_{x} \mathrm{~L}^{+}\right)^{*}$. This complex can either decompose unimolecularly back to the reactants $\left(k_{\mathrm{d}}\right)$ or can be stabilized by a collision with helium buffer gas $\left(k_{\mathrm{s}}\right)$. Consequently, the measured overall reaction rate $k_{1}$ depends on both, the helium and the reactant concentration $[\mathrm{He}]$ and $[\mathrm{L}]$, respectively. Furthermore, the cluster ion concentration in the ion trap is orders of magnitude smaller than $[\mathrm{He}]$ and $[\mathrm{L}]$, and additionally, a steady flow of the reactants and the buffer gas is ensured, which permits the postulation of pseudo-first-order kinetics. Under the applied low pressure multicollision conditions, the decomposition rate constant $k_{\mathrm{d}}$ is typically orders of magnitude larger than the stabilization $k_{\mathrm{s}}[\mathrm{He}]\left(k_{\mathrm{d}}\right.$ is usually on the order of $10^{7}$ to $10^{11} \mathrm{~s}^{-1}$, whereas $k_{\mathrm{s}}$ amounts to about $5 \cdot 10^{-10} \mathrm{~cm}^{3} \mathrm{~s}^{-1}$, and hence $\left.k_{\mathrm{s}} \cdot[\mathrm{He}]=10^{5} \mathrm{~s}^{-1}\right) .{ }^{46}$ Thus, the stabilization of the energized complex $\left(\mathrm{Pd}_{x} \mathrm{~L}^{+}\right)^{*}$ is the ratedetermining reaction step, and the pseudo-first-order rate constant in the low pressure limit is given by

$$
k_{1}=k^{(3)}[\mathrm{L}][\mathrm{He}]=k_{\mathrm{a}} k_{\mathrm{s}} / k_{\mathrm{d}}[\mathrm{L}][\mathrm{He}]
$$

The rate constants $k_{\mathrm{a}}$ and $k_{\mathrm{s}}$ are well represented by ionmolecule collision rate constants, as specified by Langevin theory, ${ }^{45 a, 47}$ and are largely temperature independent. Thus, any experimentally observed temperature dependence must be contained in the unimolecular decomposition rate constant $k_{\mathrm{d}}$. The activation barrier of this decomposition reaction results in an increase of the reaction rate with decreasing temperature for simple association reactions because the lifetime of the energized complex $\left(\mathrm{Pd}_{x} \mathrm{~L}^{+}\right) *$ increases with decreasing temperature, and stabilizing collisions become much more effective at lower temperatures. As a result, the number of adsorbed molecules on the cluster typically increases with decreasing temperature because more weakly bound complexes can also be stabilized at lower temperatures. ${ }^{46}$

In contrast, desorption of the molecule $\mathrm{L}$ from a formed and stabilized complex $\mathrm{Pd}_{x} \mathrm{~L}^{+}$

$$
\mathrm{Pd}_{x} \mathrm{~L}^{+} \rightarrow \mathrm{Pd}_{x}^{+}+\mathrm{L} \quad k_{-1}
$$

represents an activated process and can be described by the Lindemann mechanism ${ }^{45 a}$

$$
\begin{aligned}
& \mathrm{Pd}_{x} \mathrm{~L}^{+}+\mathrm{He}^{*} \rightleftarrows\left(\mathrm{Pd}_{x} \mathrm{~L}^{+}\right)^{*}+\mathrm{He} \quad k_{\mathrm{e}}, k_{\mathrm{s}} \\
& \left(\mathrm{Pd}_{x} \mathrm{~L}^{+}\right)^{*} \rightarrow \mathrm{Pd}_{x}^{+}+\mathrm{L} \quad k_{\mathrm{d}}
\end{aligned}
$$

In this model, the cluster complex $\mathrm{Pd}_{x} \mathrm{~L}^{+}$collides with an energy-rich $\mathrm{He}^{*}$ atom and becomes energized $\left(\mathrm{Pd}_{x} \mathrm{~L}^{+}\right) *$ (rate constant $k_{\mathrm{e}}$ ). Such an energized molecule can then either be deenergized (stabilized) by collision with a further $\mathrm{He}$ atom $\left(k_{\mathrm{s}}\right)$ or can decompose unimolecularly into $\mathrm{Pd}_{x}^{+}$and $\mathrm{L}\left(k_{\mathrm{d}}\right)$. However, the desorption of $\mathrm{L}$ (decomposition of $\mathrm{Pd}_{x} \mathrm{~L}^{+}$) is only possible if the helium atom $\mathrm{He}^{*}$ transfers enough energy to overcome the energy barrier for dissociation. In the lowpressure regime, the rate constant for energization thus represents the rate-limiting reaction step and the overall desorption rate constant $k_{-1}$

$$
k_{-1}=k_{e}[\mathrm{He}]
$$

only depends on the helium pressure and the rate constant for energization. Because the number of $\mathrm{He}^{*}$ containing enough energy for energization is determined by the Boltzmann distribution and thus the reaction temperature, $k_{-1}$ typically decreases with decreasing temperature.

2.B. Theoretical Methods. The theoretical explorations of the atomic arrangements and electronic structures of the $\mathrm{Pd}_{6}^{+}$ cluster and its complexes were performed with the use of firstprinciples density functional theory (DFT) calculations. In particular, we employed the Born-Oppenheimer (BO)-spin density functional (SDF)-molecular dynamics (MD) method, $\mathrm{BO}-\mathrm{SDF}-\mathrm{MD}^{48}$ with norm-conserving soft (scalar relativistic for $\mathrm{Pd}$ ) pseudopotentials ${ }^{49}$ and the generalized gradient approximation (GGA) ${ }^{50}$ for electronic exchange and correlations. In these calculations, we have used a plane-wave basis with a kinetic energy cutoff $E_{\mathrm{c}}=110 \mathrm{Ry}$, which yields convergence. This corresponds to a real-space grid spacing of $0.3 \mathrm{a}_{0}$; the real-space grid spacing for the density was $0.1 \mathrm{a}_{0}$ corresponding to $E_{\mathrm{c}}=987 \mathrm{Ry}$. In the construction of the $\mathrm{Pd}$ pseudopotentials, the valence electrons, $4 s^{2}, 4 p^{6}$, and $4 d^{10}$, were characterized by core radii $r_{\mathrm{c}}=0.85 \mathrm{a}_{0}, 0.90 \mathrm{a}_{0}$, and $1.15 \mathrm{a}_{0}$, respectively, with the $s$ orbital treated as local; $a_{0}$ is the Bohr radius. The $\mathrm{BO}-\mathrm{SDF}-\mathrm{MD}$ method is particularly suitable for investigations of charged systems because it does not employ a supercell (i.e., no periodic replication of the ionic system is used). In all the calculations, the dependence on spin multiplicity has been checked, and the results that we report correspond to the spin multiplicities with the lowest energies; for early prediction of the magnetic properties of palladium clusters, see ref 51 . Structural optimizations were performed using a conjugate-gradient-like method. 
In the first-principles calculations of the reaction profiles (pathways), a reaction coordinate was judiciously chosen; typically, the reaction coordinate consists of the distance between two atoms of the reactant molecules (for example an $\mathrm{O}$ atom of an adsorbed oxygen molecule and the $\mathrm{C}$ atom of a reacting $\mathrm{CO}$ molecule). For each value of the reaction coordinate, the total energy of the system was optimized through unconstrained relaxation of all of the other degrees of freedom of the system (reactants, other adsorbents, and Pd cluster atoms). The reaction profiles (reaction paths) were obtained via repeating such calculations for various values of the chosen reaction coordinate. These calculations yield results that are the same as, or close to, those obtained by other methods (e.g., the nudged elastic band and variants thereof); see the discussion on pp 89 and 90 in ref $20 \mathrm{f}$.

\section{RESULTS AND DISCUSSION}

3.A. Rate Constants for $\mathrm{O}_{2}$ and $\mathrm{CO}$ Adsorption and Desorption. Among all the investigated clusters, $\mathrm{Pd}_{2}^{+}, \mathrm{Pd}_{3}^{+}$, and the oxides $\mathrm{Pd}_{2} \mathrm{O}^{+}$and $\mathrm{Pd}_{3} \mathrm{O}^{+}$rapidly decompose via loss of neutral $\mathrm{Pd}$ atoms upon reaction with $\mathrm{CO}$ under the applied experimental conditions. ${ }^{39}$ Furthermore, $\mathrm{Pd}_{7}^{+}$and $\mathrm{Pd}_{7} \mathrm{O}^{+}$were found to fragment after the reaction with $\mathrm{O}_{2}$ as well, exclusively yielding the stable six-atomic palladium-oxide $\mathrm{Pd}_{6} \mathrm{O}_{4}{ }^{+35 a, 36}$ Similar fragmentation behavior of these clusters was also observed in the presence of an $\mathrm{O}_{2} / \mathrm{CO}$ mixture. Thus, $\mathrm{Pd}_{2}^{+}$, $\mathrm{Pd}_{3}{ }^{+}$, and $\mathrm{Pd}_{7}^{+}$(as well as the corresponding oxides) are not suitable model systems for a detailed investigation of the $\mathrm{CO}$ oxidation reaction and will not be discussed further here; instead, we will focus exclusively on the palladium clusters $\mathrm{Pd}_{4}^{+}$, $\mathrm{Pd}_{5}{ }^{+}$, and $\mathrm{Pd}_{6}{ }^{+}$(as well as on the corresponding mono-oxides).

Figure 1a displays the experimentally obtained termolecular rate constants $k^{(3)}$ (cf. eqs 1-3, Experimental and Computational Methods) for the adsorption of a first $\mathrm{O}_{2}$ molecule (black squares) onto $\mathrm{Pd}_{x}^{+}(x=4-6){ }^{35 b, 36}$ These data show the increasing reactivity of these $\mathrm{Pd}$ clusters toward $\mathrm{O}_{2}$ with increasing clusters size (see also Table 1 ). In contrast, the rate constant for the adsorption of a first $\mathrm{CO}$ molecule is similar for $\mathrm{Pd}_{4}^{+}$and $\mathrm{Pd}_{6}^{+}$, whereas $\mathrm{Pd}_{5}^{+}$shows enhanced reactivity (Figure $1 \mathrm{a}$, red circles, and Table 1). In this latter case, due to the fast reaction of $\mathrm{Pd}_{x}^{+}$with $\mathrm{CO}$ even at low $\mathrm{CO}$ partial pressure, ${ }^{39}$ the experimental determination of reliable rate constants was only possible for $\mathrm{Pd}_{4}^{+}$(green triangle in Figure 1a). Therefore, the rate constants describing the $\mathrm{CO}$ adsorption reaction have been deduced from theoretical binding energies ${ }^{40 \mathrm{~h}}$ by employing RRKM theory ${ }^{52}$ and the Lindemann energy transfer model for association reactions ${ }^{45 a}$ (red circles in Figure 1a, cf. eq 2 in Experimental and Computational Methods). For $\mathrm{Pd}_{4}{ }^{+}$the thus obtained value amounts to $61 \times 10^{-27} \mathrm{~cm}^{6} \mathrm{~s}^{-1}$, which is in excellent agreement with the experimental value listed in Table 1.

The desorption of $\mathrm{O}_{2}$ and $\mathrm{CO}$, respectively, from the once formed and stabilized complexes $\mathrm{Pd}_{x} \mathrm{O}_{2}^{+}$and $\mathrm{Pd}_{x} \mathrm{CO}^{+}$is an activated process that can be described by a Lindemann-type reaction schema, ${ }^{45 a}$ as detailed in eq 5 (Experimental and Computational Methods). Under the applied low-pressure conditions (total pressure of about $1 \mathrm{~Pa}$ ), the overall reaction rate constant $k_{-1}$ for the desorption of the ligands (reaction eq 4 in Experimental and Computational Methods) can be considered to be determined by the energization of $\mathrm{Pd}_{x} \mathrm{O}_{2}^{+}$ and $\mathrm{Pd}_{x} \mathrm{CO}^{+}$via collision with an energy-rich $\mathrm{He}^{*}$ atom (eqs 5a, 5b, and 6, Experimental and Computational Methods). The experimentally obtained energization rate constants $k_{\mathrm{e}}$ for

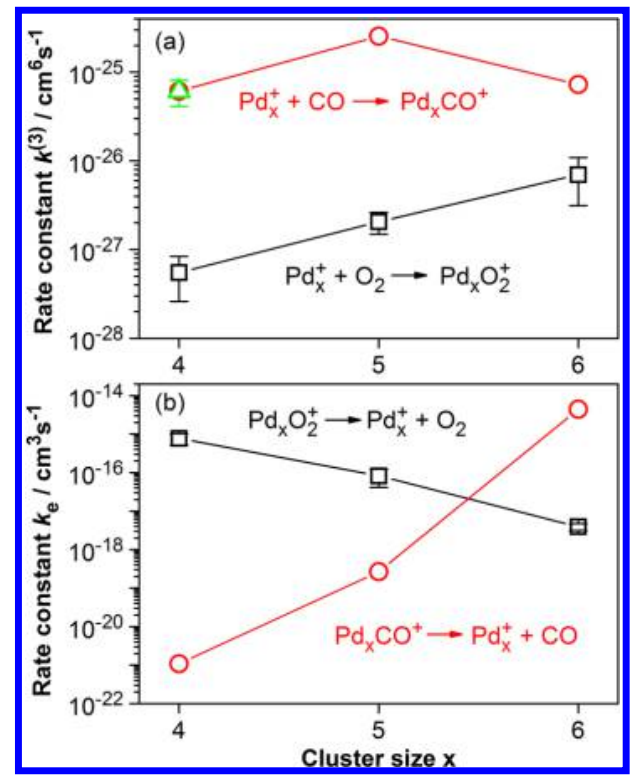

Figure 1. (a) Experimentally obtained termolecular rate constant $k^{(3)}$ for the adsorption of a first $\mathrm{O}_{2}$ molecule (black squares) onto $\mathrm{Pd}_{x}^{+}(\mathrm{x}$ $=4-6)$ and of a first $\mathrm{CO}$ molecule onto $\mathrm{Pd}_{4}{ }^{+}$(green triangle). The rate constants $k^{(3)}$ for the reaction $\mathrm{Pd}_{x}^{+}+\mathrm{CO} \rightarrow \mathrm{Pd}_{x} \mathrm{CO}^{+}$(red circles) have been deduced from theoretical $\mathrm{Pd}_{x}{ }^{+}$-CO binding energies ${ }^{40 \mathrm{~h}}$ by employing RRKM theory ${ }^{52}$ and the Lindemann energy transfer model for association reactions (see Experimental and Computational Methods). ${ }^{45 a}$ (b) Energization rate constants, $k_{\mathrm{e}}$ (cf. eqs 4-6), for the desorption of the ligands from the stabilized complexes $\mathrm{Pd}_{x} \mathrm{O}_{2}{ }^{+}$ (black squares, experimental values) and $\mathrm{Pd}_{x} \mathrm{CO}^{+}$(red circles, estimated values obtained by applying the Hinshelwood-Lindemann theory $\left.{ }^{45 a}\right)$. Lines are only drawn as a guide to the eye.

Table 1. Termolecular Rate Constants $k^{(3)}$ for the Adsorption of a First $\mathrm{O}_{2}$ and $\mathrm{CO}$ Molecule, Respectively, On Different Palladium Clusters $\mathbf{P d}_{x}{ }^{+}$as well as Energization Rate Constants $k_{\mathrm{e}}$ for the Ligand Desorption from the Complexes $\mathrm{Pd}_{x} \mathrm{O}_{2}^{+}$and $\mathrm{Pd}_{x} \mathrm{CO}^{+}$

$\begin{array}{lcccc}\mathrm{Pd}_{x}^{+} & \begin{array}{c}k^{(3)}\left(\mathrm{O}_{2}\right) \\ {\left[10^{-27} \mathrm{~cm}^{6} \mathrm{~s}^{-1}\right]^{a}}\end{array} & \begin{array}{c}k^{(3)}(\mathrm{CO}) \\ {\left[10^{-27} \mathrm{~cm}^{6} \mathrm{~s}^{-1}\right]}\end{array} & \begin{array}{c}k_{\mathrm{e}}\left(\mathrm{Pd}_{x} \mathrm{O}_{2}^{+}\right) \\ {\left[10^{-17} \mathrm{~cm}^{3} \mathrm{~s}^{-1}\right]^{a}}\end{array} & \begin{array}{c}k_{\mathrm{e}}\left(\mathrm{Pd}_{x} \mathrm{CO}^{+}\right) \\ {\left[10^{-17} \mathrm{~cm}^{3} \mathrm{~s}^{-1}\right]^{b}}\end{array} \\ \mathrm{Pd}_{4}^{+} & 0.55 \pm 0.29 & 61 \pm 20^{a} & 78 \pm 26 & 0.00011 \\ \mathrm{Pd}_{5}^{+} & 2.1 \pm 0.6 & 250^{b} & 8.2 \pm 4.1 & 0.027 \\ \mathrm{Pd}_{6}^{+} & 7.0 \pm 3.9 & 73^{b} & 0.39 \pm 0.08 & 443\end{array}$

${ }^{a}$ Experimentally obtained values. ${ }^{b}$ Estimated values; for details, see text.

$\mathrm{Pd}_{x} \mathrm{O}_{2}{ }^{+}$are displayed in Figure $1 \mathrm{~b}$ as black squares (cf. Table 1), illustrating a decreasing probability for $\mathrm{O}_{2}$ desorption with increasing cluster size. In contrast, the energization rate constants $k_{\mathrm{e}}$ for $\mathrm{Pd}_{x} \mathrm{CO}^{+}$(red circles in Figure $1 \mathrm{~b}$ ), which have been estimated by employing the HinshelwoodLindemann theory, ${ }^{45 a}$ demonstrate a strongly increasing CO desorption probability with increasing cluster size.

Comparing the cluster-size dependence of the rate constants for the oxygen adsorption with the corresponding rate constants for oxygen ligand desorption in Figure 1 and Table 1 reveals that $\mathrm{O}_{2}$ most strongly reacts with $\mathrm{Pd}_{6}^{+}$, and accordingly, the desorption of $\mathrm{O}_{2}$ from $\mathrm{Pd}_{6} \mathrm{O}_{2}{ }^{+}$is the slowest among all investigated clusters. The comparably large desorption rate constant of $\mathrm{O}_{2}$ from $\mathrm{Pd}_{4}^{+}$was explained by theoretical simulations to be due to the molecular adsorption and subsequent activated dissociation of $\mathrm{O}_{2}$ on this particular cluster. ${ }^{36}$ In contrast, a reverse cluster-size dependence of $k_{\mathrm{e}}$ is 
observed for $\mathrm{Pd}_{x} \mathrm{CO}^{+}$. The rather high $\mathrm{CO}$ binding energy on $\mathrm{Pd}_{4}^{+}\left(132 \mathrm{~kJ} \mathrm{~mol}^{-140 \mathrm{~h}}\right)$ and $\mathrm{Pd}_{5}^{+}\left(127 \mathrm{~kJ} \mathrm{~mol}^{-140 \mathrm{~h}}\right)$ results in very small desorption rate constants for these cluster sizes, whereas the reduced $\mathrm{CO}$ binding energy on $\mathrm{Pd}_{6}^{+}(103 \mathrm{~kJ}$ $\mathrm{mol}^{-140 \mathrm{~h}}$ ) leads to an increase of $k_{\mathrm{e}}$ by several orders of magnitude.

Interestingly, the final products of all three clusters $\mathrm{Pd}_{4-6}{ }^{+}$ after reaction with $\mathrm{O}_{2}$ under thermal equilibrium conditions are exclusively the tetra-oxide complexes $\mathrm{Pd}_{x} \mathrm{O}_{4}{ }^{+35 a, 36}$ Only at cryogenic temperatures are more weakly bound oxygen molecules adsorbed. In contrast, the reactions with carbon monoxide lead to instant multiple $\mathrm{CO}$ adsorption yielding the carbonyl complexes $\mathrm{Pd}_{4}(\mathrm{CO})_{8-10}{ }^{+}, \mathrm{Pd}_{5}(\mathrm{CO})_{9-11}{ }^{+}$, and $\mathrm{Pd}_{6}(\mathrm{CO})_{9-13}{ }^{+}$with the maximum number of adsorbed $\mathrm{CO}$, depending on the reaction temperature. ${ }^{39}$

In the following sections, we will present experimental and theoretical results obtained for the catalytic $\mathrm{CO}$ oxidation mediated by the model systems $\mathrm{Pd}_{4}^{+}, \mathrm{Pd}_{5}{ }^{+}$, and $\mathrm{Pd}_{6}{ }^{+}$in order to gain insight into the importance of $\mathrm{O}_{2}$ adsorption and dissociation on the cluster, as well as of the $\mathrm{CO}$ adsorption strength for the low-temperature $\mathrm{CO}$ combustion. These data will be interpreted on the basis of the above presented rate constants for ligand adsorption and desorption, and the results will be compared with fundamental findings on extended $\mathrm{Pd}$ surfaces, supported Pd nanoparticles, and clusters.

3.B. $\mathrm{CO}$ Oxidation Mediated by $\mathrm{Pd}_{4}{ }^{+}$. From Figure 1a and Table 1 it is apparent that for all three clusters, $\mathrm{Pd}_{4}{ }^{+}, \mathrm{Pd}_{5}{ }^{+}$, and $\mathrm{Pd}_{6}^{+}$, the $\mathrm{CO}$ adsorption rate constant exceeds the $\mathrm{O}_{2}$ adsorption rate constant by at least one order of magnitude. Therefore, in the experiments described in the following, in which the catalytic activity of these clusters is investigated by introducing a mixture of $\mathrm{O}_{2}$ and $\mathrm{CO}$ into the ion trap, an excess of oxygen is always provided to partly compensate for the reactivity differences.

Figure 2 displays the ion mass distribution (Figure 2a) and the corresponding kinetic data (Figure $2 b$ ) for the reaction between $\mathrm{Pd}_{4}^{+}$and an 11:1 mixture of $\mathrm{O}_{2}$ and $\mathrm{CO}$. At these pressure conditions, $\mathrm{Pd}_{4}^{+}$reacts to form the products $\mathrm{Pd}_{4} \mathrm{CO}^{+}$, $\mathrm{Pd}_{4} \mathrm{O}(\mathrm{CO})_{5}{ }^{+}, \mathrm{Pd}_{4} \mathrm{O}(\mathrm{CO})_{6}{ }^{+}$, and $\mathrm{Pd}_{4} \mathrm{O}_{2}(\mathrm{CO})_{6}{ }^{+}$, with $\mathrm{Pd}_{4} \mathrm{O}$ $(\mathrm{CO})_{5}{ }^{+}$representing the dominant product at all reaction times. Please note that a formal adsorption-stoichiometry $\mathrm{Pd}_{4} \mathrm{O}(\mathrm{CO})_{y}^{+}$does not exclude the presence of $\mathrm{Pd}_{4}\left(\mathrm{CO}_{2}\right)$ (CO $)_{y-1}{ }^{+}$complexes. The kinetic data reveal that $\mathrm{Pd}_{4} \mathrm{CO}^{+}$is formed first, but the signal disappears after about $0.4 \mathrm{~s}$. The adsorption of $\mathrm{CO}$ as the first reaction step is in agreement with the fact that the rate constants determined for the adsorption of $\mathrm{CO}$ onto $\mathrm{Pd}_{4}^{+}$is more than two orders of magnitude larger than the $\mathrm{O}_{2}$ adsorption rate constant (cf. Figure la and Table 1). Also, the single product $\mathrm{Pd}_{4} \mathrm{O}_{4}{ }^{+}$, which is detected when only $\mathrm{O}_{2}$ is the reaction gas (see discussion above), is not observed at all in the presence of a $\mathrm{O}_{2} / \mathrm{CO}$ reaction gas mixture.

Furthermore, a comparably large $\mathrm{O}_{2}$ desorption rate constant was found for $\mathrm{Pd}_{4} \mathrm{O}_{2}^{+}$(cf. Figure $1 \mathrm{~b}$ ), although it can be assumed that $\mathrm{CO}$ does not desorb from $\mathrm{Pd}_{4}{ }^{+}$because $\mathrm{CO}$ binds strongly (experimental value determined from the measured rate constant: $132 \pm 7 \mathrm{~kJ} \mathrm{~mol}^{-1}$, theoretical value: $132.2 \mathrm{~kJ}$ $\left.\mathrm{mol}^{-140 \mathrm{~h}}\right)$, resulting in an extremely small rate constant for decomposition of $\mathrm{Pd}_{4} \mathrm{CO}^{+}$(cf. Figure $1 \mathrm{~b}$ ). Thus, the adsorption of $\mathrm{CO}$ can be considered the first adsorption step even under $\mathrm{O}_{2}$-rich pressure conditions, and the adsorption of multiple $\mathrm{CO}$ is also likely, as was observed in the experiment.

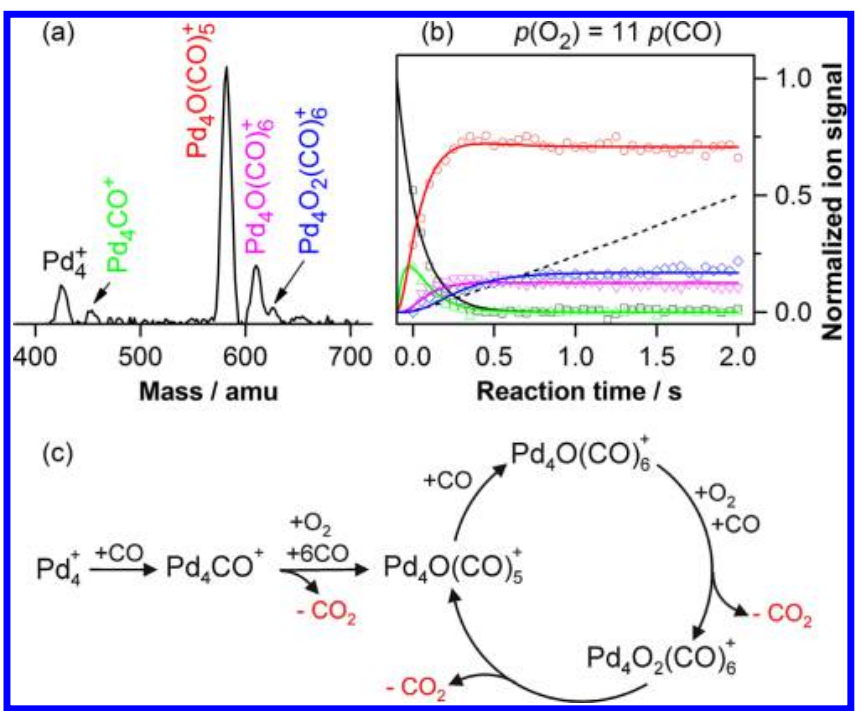

Figure 2. (a) Ion mass distribution (0.1 s reaction time) and (b) kinetics (open symbols) obtained from the reaction between $\mathrm{Pd}_{4}{ }^{+}$and a 11:1 $\mathrm{O}_{2} / \mathrm{CO}$ mixture at room temperature $\left(p\left(\mathrm{O}_{2}\right)=0.100 \mathrm{~Pa}\right.$, $p(\mathrm{CO})=0.009 \mathrm{~Pa})$. The dashed line indicates the $\mathrm{CO}_{2}$ production simulated on the basis of the proposed mechanism. (c) Proposed reaction mechanism that best fits the experimental data under these pressure conditions. The solid lines in (b) are obtained by fitting the integrated rate equations of this mechanism to the experimental data.

Additional reactivity experiments with already preoxidized $\mathrm{Pd}_{4} \mathrm{O}^{+}$and an oxygen-rich $\mathrm{O}_{2} / \mathrm{CO}$ mixture result in identical ion mass distributions, as observed for the bare $\mathrm{Pd}_{4}^{+}$(Figure 2a). The room-temperature reaction of $\mathrm{Pd}_{4} \mathrm{O}^{+}$with $\mathrm{O}_{2}$ only has recently been shown ${ }^{36}$ to result in the formation of $\mathrm{Pd}_{4} \mathrm{O}_{3}{ }^{+}$and $\mathrm{Pd}_{4} \mathrm{O}_{5}^{+}$, whereas $\mathrm{Pd}_{4} \mathrm{O}^{+}$reacts with $\mathrm{CO}$ to yield $\mathrm{Pd}_{4}^{+}$through formation and desorption of $\mathrm{CO}_{2} \cdot{ }^{39}$ Consequently, the observation of identical product ion mass distributions for both $\mathrm{Pd}_{4} \mathrm{O}^{+}$and $\mathrm{Pd}_{4}^{+}$lacking any of the typical oxidation products $\mathrm{Pd}_{4} \mathrm{O}_{3}{ }^{+}, \mathrm{Pd}_{4} \mathrm{O}_{4}{ }^{+}$, or $\mathrm{Pd}_{4} \mathrm{O}_{5}{ }^{+}$leads to the conclusion that $\mathrm{CO}$ adsorption must represent the first and dominating reaction step. In the case of $\mathrm{Pd}_{4} \mathrm{O}^{+}$, this first yields the bare palladium tetramer, which then further reacts to form the typical $\mathrm{Pd}_{4}^{+}$reaction products.

With respect to the measured reaction kinetics (Figure 2b), it is important to note that all observed products (except $\mathrm{Pd}_{4} \mathrm{CO}^{+}$) exhibit constant, nonvanishing concentrations after about $0.5 \mathrm{~s}$ reaction time. This is indicative of an equilibrium reaction mechanism. As the products $\mathrm{Pd}_{4} \mathrm{O}(\mathrm{CO})_{5}{ }^{+}$and $\mathrm{Pd}_{4} \mathrm{O}(\mathrm{CO})_{6}^{+}$do contain dissociated oxygen, $\mathrm{CO}_{2}$ must have been liberated in the process of formation of these products. Any conceivable alternative (liberation of $\mathrm{C}+\mathrm{O}+\mathrm{O}, \mathrm{O}+\mathrm{CO}$, or $\mathrm{O}_{2}+\mathrm{C}$ ) is clearly thermodynamically unfavorable compared to the liberation of $\mathrm{CO}_{2}$. In most cases, the energy required to liberate a bound $\mathrm{O}$ or $\mathrm{C}$ atom will exceed other binding energies in the cluster complex, and thus, the cluster will decompose, which is not observed for the cluster systems investigated here. Hence, it is clear that $\mathrm{CO}_{2}$ is liberated during the formation of the respective products, even though only charged species are measured directly in the present experimental setup. However, to sustain equilibrium reactions between these products and $\mathrm{Pd}_{4} \mathrm{O}_{2}(\mathrm{CO})_{6}^{+}, \mathrm{CO}_{2}$ would be required to be present in the ion trap, which is not the case. The concentration of the catalytically formed $\mathrm{CO}_{2}$ is about 6 orders of magnitude smaller than the concentrations of $\mathrm{O}_{2}$ and $\mathrm{CO}$ and can thus be neglected. ${ }^{42}$ This is clearly an excess 
reactant situation according to the principle of Le Chatelier, even considering the involvement of palladium as a catalyst. As a consequence, the forward $\mathrm{CO}_{2}$ formation reaction is strongly favored-expressed differently: forward $\mathrm{CO}_{2}$ formation must occur exclusively as the $\mathrm{CO}$ and $\mathrm{O}_{2}$ concentrations are constant in the experiment, and $\mathrm{CO}_{2}$ will leave the ion trap. Thus, the measured equilibrium type reaction kinetics cannot be explained by a simple equilibrium mechanism. Consequently, the only conceivable explanation for the constant, nonvanishing product concentrations in the kinetics is a catalytic reaction cycle.

A possible reaction mechanism including such a catalytic reaction cycle, which is proposed on the basis of the observed ion mass distributions and kinetics and which best fits the kinetic data, is displayed in Figure 2c. This mechanism shows that $\mathrm{CO}$ oxidation is indeed possible in the case of $\mathrm{Pd}_{4}^{+}$, yet, interestingly, with the (pre-) oxidized (and apparently $\mathrm{CO}$ covered) cluster as catalytically active species. We note that here, and elsewhere in this paper, we refer to $\mathrm{Pd}_{x} \mathrm{O}^{+}(x=4-6)$ as the (mono) oxidized cluster, or (pre-) oxidized cluster, to distinguish it from the bare $\mathrm{Pd}_{x}^{+}$cluster serving as a catalyzing substrate for the $\mathrm{CO}$ oxidation reaction. Similarly, we refer to $\mathrm{Pd}_{x} \mathrm{O}_{y}{ }^{+}$clusters as oxide (or nano-oxide) clusters. This, by itself, does not imply that these oxygen-containing clusters have the same stoichiometry, structure, or properties as the bulk oxide $(\mathrm{PdO})$ or the surface oxides reviewed in the introductory section; we remark here that even in the case of extended surface systems, the electronic properties of the ultrathin surface oxides (see discussion in section 1.A), for example, $\mathrm{Pd}_{5} \mathrm{O}_{4}$ formed ${ }^{9 \mathrm{~b}}$ on $\mathrm{Pd}(111)$, differ greatly from those of the bulk oxide; in particular, the former catalyzes the $\mathrm{CO}$ oxidation reaction, whereas the latter $(\mathrm{PdO})$ does not. To distinguish between chemisorbed oxygen atoms and "oxidic" oxygens would require high-resolution core spectroscopy measurements (see, e.g., ref 9b) that are outside the scope of our gas phase ion-trap measurements.

As stated above, recent reactivity studies of preoxidized $\mathrm{Pd}_{4} \mathrm{O}^{+}$(and also $\mathrm{Pd}_{4} \mathrm{O}_{2}^{+}$) containing atomic oxygen with $\mathrm{CO}$ showed the fast formation and desorption of $\mathrm{CO}_{2}$ under reformation of the bare cluster $\mathrm{Pd}_{4}{ }^{+} \cdot{ }^{39}$ Thus, it can be assumed that carbon dioxide is formed fast as soon as $\mathrm{O}_{\mathrm{ad}}$ and $\mathrm{CO}_{\mathrm{ad}}$ are coadsorbed on the cluster and in agreement with studies on $\mathrm{Pd}$ single crystals as well as supported nanoparticles and clusters, the reaction is largely determined by dissociative $\mathrm{O}_{2}$ adsorption and the adsorption strength of $\mathrm{CO} .^{3 \mathrm{~b}, 21 \mathrm{~b}}$ We note here that no additional oxygen was supplied to the ion trap in these previous experiments, ${ }^{35}$ and hence, no coadsorption products were observed in these cases for $\mathrm{Pd}_{4}^{+}$, in contrast to the present experiments, in which a large oxygen excess was employed.

Separate adsorption experiments performed with only $\mathrm{CO}_{2}$ in the ion trap demonstrate that all the clusters interact very weakly with carbon dioxide (very similar to the results of surface studies and in accordance with our calculations for $\mathrm{Pd}_{6}^{+}$ shown below). At room temperature only the clusters with three and four palladium atoms exhibit noticeable $\mathrm{CO}_{2}$ adsorption signals and only at comparably high partial pressures of $>10 \% \mathrm{CO}_{2}$ in the ion trap. This confirms the facile desorption of readily formed $\mathrm{CO}_{2}$. In addition, $\mathrm{CO}_{2}$ is found to be easily replaced by coadsorbed carbon monoxide molecules. ${ }^{39}$

Due to the slow $\mathrm{O}_{2}$ adsorption and dissociation in conjunction with the strong $\mathrm{CO}$ binding at room temperature, the $\mathrm{CO}$ combustion reaction on $\mathrm{Pd}_{4}^{+}$is, however, apparently not very effective, and the cluster is covered by five to six $\mathrm{CO}$ molecules, even under $\mathrm{O}_{2}$-rich pressure conditions. This conclusion is supported by the comparably small catalytic turnover frequency of $0.26 \pm 0.05 \mathrm{CO}_{2}$ molecules per second and cluster (which has been determined for $\mathrm{Pd}_{4}{ }^{+}$from the kinetics in Figure $2 \mathrm{~b}$ by simulating the emerging $\mathrm{CO}_{2}$ product concentration as a function of the reaction time on the basis of the deduced rate constants) compared to, for example, $2.3 \pm$ $0.5 \mathrm{CO}_{2}$ molecules per second for $\mathrm{Pd}_{6} \mathrm{O}^{+}$(see also discussion below).

On $\operatorname{Pd}(111)$, the $\mathrm{CO}$ oxidation becomes effective, if the temperature exceeds about $450 \mathrm{~K}^{3 \mathrm{~b}}$ The desorption of $\mathrm{CO}$ is the key for opening surface sites to activate $\mathrm{O}_{2}$. At this temperature, the rate constant for $\mathrm{CO}$ desorption ${ }^{6 c}$ has been determined to amount to between $0.15 \mathrm{~s}^{-1}$ and $5 \times 10^{-4} \mathrm{~s}^{-1}$. This value is several orders of magnitude larger than the estimated room-temperature decomposition rate constant for $\operatorname{Pd}_{4} \mathrm{CO}^{+}\left(k_{\mathrm{e}}=1.1 \times 10^{-21} \mathrm{~cm}^{3} \mathrm{~s}^{-1}\right.$ and $k_{-1} \sim 10^{-7} \mathrm{~s}^{-1}$, respectively (cf. eq $6, p(\mathrm{He})=1 \mathrm{~Pa})$ ). Considering the binding energy of $\mathrm{CO}$ to $\mathrm{Pd}_{4}^{+}\left(132 \pm 7 \mathrm{~kJ} \mathrm{~mol}^{-1}\right)$ determined in the present study, a rough estimate reveals that also for $\mathrm{Pd}_{4}^{+}$a reaction temperature of at least $380 \mathrm{~K}$ would be required to achieve desorption rate constants of $>5 \times 10^{-4} \mathrm{~s}^{-1}$, which is in surprisingly good agreement with the effective $\mathrm{CO}$ oxidation conditions on Pd single crystals. Nevertheless, in the present cases, the mass spectra in Figure 2a indicate that chemisorbed $\mathrm{O}$ and $\mathrm{CO}$ coexist on a particle even at room temperature, which hints toward fundamental differences between the catalytic mechanisms and supports the suggestion that the (pre-) oxidized palladium clusters are the actual active catalysts.

3.C. CO Oxidation Mediated by $\mathrm{Pd}_{5}{ }^{+}$. In the case of the cluster $\mathrm{Pd}_{5}^{+}$, both the $\mathrm{O}_{2}$ and $\mathrm{CO}$ adsorption rates increase compared to the case of the $\mathrm{Pd}_{4}^{+}$cluster, cf. Figure $1 \mathrm{a}$ and Table 1. However, the $\mathrm{O}_{2}$ desorption is less likely, whereas the $\mathrm{CO}$ desorption rate is found to increase for $\mathrm{Pd}_{5}{ }^{+}$, cf. Figure $1 \mathrm{~b}$ and Table 1 . This has profound consequences for the catalytic activity of this cluster $\mathrm{Pd}_{5}^{+}$.

Figure 3 a displays a representative ion mass distribution detected after the reaction of $\mathrm{Pd}_{5}{ }^{+}$with a 13:1 $\mathrm{O}_{2} / \mathrm{CO}$ mixture for $0.1 \mathrm{~s}$, showing the oxygen-rich products $\mathrm{Pd}_{5} \mathrm{O}_{3}{ }^{+}, \mathrm{Pd}_{5} \mathrm{O}_{4}{ }^{+}$, $\mathrm{Pd}_{5} \mathrm{O}_{3} \mathrm{CO}^{+}$, as well as the CO-rich $\mathrm{Pd}_{5} \mathrm{O}(\mathrm{CO})_{6}{ }^{+}$. The preferred occurrence of oxygen-rich products at early reaction times reflects the increased $\mathrm{O}_{2}$ adsorption and decreased $\mathrm{O}_{2}$

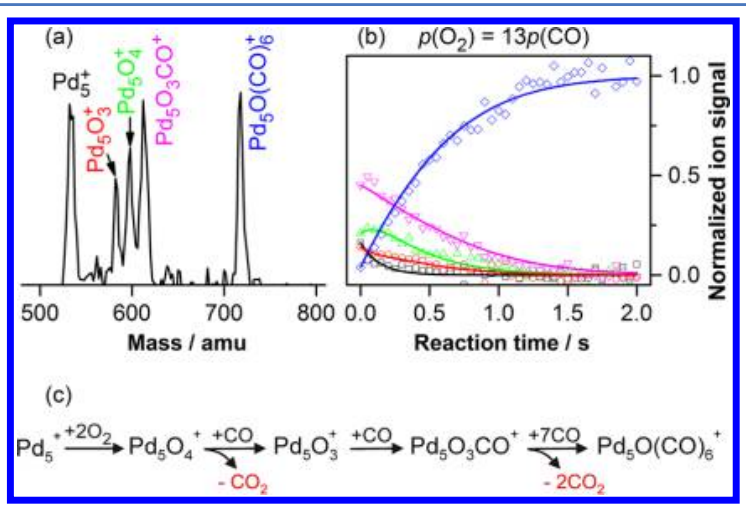

Figure 3. (a) Ion mass distributions (0.1 s reaction time) and (b) kinetics (open symbols) obtained from the reaction between $\mathrm{Pd}_{5}{ }^{+}$and a 13:1 $\mathrm{O}_{2} / \mathrm{CO}$ mixture at room temperature $\left(p\left(\mathrm{O}_{2}\right)=0.100 \mathrm{~Pa}\right.$, $p(\mathrm{CO})=0.008 \mathrm{~Pa})$. (c) Proposed reaction mechanism that best fits the experimental data under these pressure conditions. The solid lines in (b) are obtained by fitting the integrated rate equations of this mechanism to the experimental data. 
desorption rate constant compared to $\mathrm{Pd}_{4}^{+}$(cf. Figure 1). Because oxidation studies of $\mathrm{Pd}_{5}{ }^{+}$revealed $\mathrm{Pd}_{5} \mathrm{O}_{4}{ }^{+}$as the only reaction product, ${ }^{35 \mathrm{~b}, 36}$ the formation of $\mathrm{Pd}_{5} \mathrm{O}_{3}{ }^{+}$and $\mathrm{Pd}_{5} \mathrm{O}_{3} \mathrm{CO}^{+}$ in the presence of an $\mathrm{O}_{2} / \mathrm{CO}$ mixture gives first indications for a successful $\mathrm{CO}$ oxidation mechanism at these early reaction times $\left(t_{\mathrm{R}}<1.0 \mathrm{~s}\right)$.

At longer reaction time, however, the complexes $\mathrm{Pd}_{5} \mathrm{O}_{3}{ }^{+}$, $\mathrm{Pd}_{5} \mathrm{O}_{4}^{+}, \mathrm{Pd}_{5} \mathrm{O}_{3} \mathrm{CO}^{+}$completely disappear, and the CO-rich product, $\mathrm{Pd}_{5} \mathrm{O}(\mathrm{CO})_{6}{ }^{+}$, remains the only observable reaction product (see kinetics in Figure $3 \mathrm{~b}$ ). This observation indicates that the reaction of adsorbed $\mathrm{O}$ with $\mathrm{CO}$ is fast and facile also in the case of $\mathrm{Pd}_{5}^{+}$, but only as long as not too many $\mathrm{CO}$ are adsorbed. The cluster-size-dependent competition between $\mathrm{CO}$ adsorption and combustion on oxidized palladium clusters has been detailed in a previous contribution. ${ }^{39}$ The dominant $\mathrm{CO}$ adsorption is in line with the enhanced $\mathrm{CO}$ adsorption rate constant of this cluster, as apparent from Figure 1a. In the process of the formation of the final product, $\mathrm{Pd}_{5} \mathrm{O}(\mathrm{CO})_{6}^{+}$, $\mathrm{CO}_{2}$ must again be formed and liberated. Yet, apparently no catalytic cycle is operative. The corresponding most simple reaction mechanism that best fits the kinetic data is depicted in Figure 3c.

3.D. CO Oxidation Mediated by $\mathrm{Pd}_{6}{ }^{+}$. Room-Temperature $\mathrm{CO}$ Oxidation. $\mathrm{Pd}_{6}{ }^{+}$reacts with oxygen the strongest among the investigated clusters, exhibiting the largest $\mathrm{O}_{2}$ adsorption rate constant and the smallest $\mathrm{O}_{2}$ desorption rate constant (see Figure 1 and Table 1). The adsorption of $\mathrm{O}_{2}$ can also compete strongly with the $\mathrm{CO}$ adsorption under the applied oxygen-rich conditions because both adsorption rate constants differ only by about 1 order of magnitude for $\mathrm{Pd}_{6}^{+}$. But even more importantly, the $\mathrm{CO}$ desorption rate constant exceeds that of $\mathrm{O}_{2}$ by about 3 orders of magnitude in the case of $\mathrm{Pd}_{6}^{+}$(cf. Figure $1 \mathrm{~b}$ and Table 1 ). These facts are in line with the observation of mostly (essentially exclusively) oxygencontaining products, when $\mathrm{Pd}_{6}{ }^{+}$is reacted with a 9:1 mixture of $\mathrm{O}_{2}$ and $\mathrm{CO}$ for $0.1 \mathrm{~s}$ in the ion trap (see mass spectrum in Figure 4a). ${ }^{35 \mathrm{a}}$ Apart from the main product, $\mathrm{Pd}_{6} \mathrm{O}_{4}{ }^{+}$, additional ion signals corresponding to $\mathrm{Pd}_{6} \mathrm{O}_{3}{ }^{+}, \mathrm{Pd}_{6} \mathrm{O}_{5}{ }^{+}$, and $\mathrm{Pd}_{6} \mathrm{O}_{5}(\mathrm{CO})^{+}$ are detected. The odd number of oxygen atoms in these products and their immediate formation (cf. kinetics in Figure

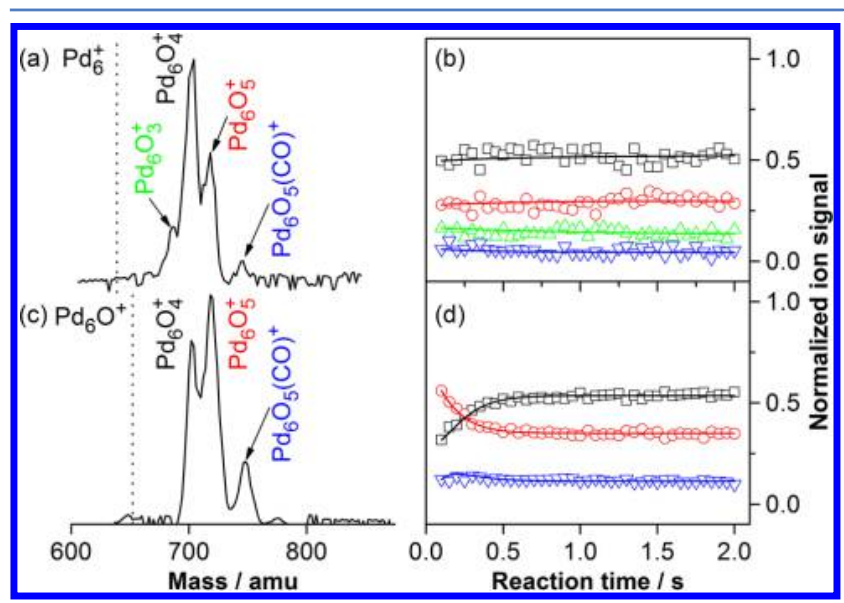

Figure 4. Representative ion mass distributions obtained at a reaction time of $0.1 \mathrm{~s}$ and corresponding kinetics of the reaction between $(\mathrm{a}, \mathrm{b})$ $\mathrm{Pd}_{6}^{+}$and $\mathrm{O}_{2} / \mathrm{CO}$ as well as $(\mathrm{c}, \mathrm{d}) \mathrm{Pd}_{6} \mathrm{O}^{+}$and $\mathrm{O}_{2} / \mathrm{CO}$ recorded at 300 K. $(\mathrm{a}, \mathrm{b}): p\left(\mathrm{O}_{2}\right)=9 p(\mathrm{CO})\left(p\left(\mathrm{O}_{2}\right)=0.09 \mathrm{~Pa}, p(\mathrm{CO})=0.01 \mathrm{~Pa}\right)$; $(\mathrm{c}, \mathrm{d}): p\left(\mathrm{O}_{2}\right)=8 \mathrm{p}(\mathrm{CO})\left(p\left(\mathrm{O}_{2}\right)=0.040 \mathrm{~Pa}, p(\mathrm{CO})=0.005 \mathrm{~Pa}\right)$. 4b) already leads us to expect $\mathrm{Pd}_{6}^{+}$to be the most active candidate for the catalytic oxidation of $\mathrm{CO}$.

Indeed, $\mathrm{Pd}_{6} \mathrm{O}_{4}^{+}$was detected as the sole product of the reaction of $\mathrm{Pd}_{6}^{+}$with $\mathrm{O}_{2}$ over a large temperature range. ${ }^{35 a, 36}$ The additional products, containing an odd number of oxygen atoms in the mass spectrum in Figure $4 a$, are only observed in the presence of an $\mathrm{O}_{2} / \mathrm{CO}$ mixture, indicating the fast reaction of $\mathrm{CO}$ with the adsorbed oxygen leading to the release of $\mathrm{CO}_{2}$. Analogous to $\mathrm{Pd}_{4}^{+}$(dashed black line in Figure 2b; TOF: 0.26 $\pm 0.05 \mathrm{CO}_{2} \mathrm{~s}^{-1}$ ) also in the case of $\mathrm{Pd}_{6}^{+}$the rate of $\mathrm{CO}_{2}$ release can be calculated yielding an about 1 order of magnitude larger value of $2.3 \pm 0.5 \mathrm{~s}^{-1}$.

The corresponding kinetic data (Figure 4b) show, under the applied experimental conditions, a rapid saturation of all products (faster than the time resolution of the experiment). Such kinetic data can either be explained by an equilibrium reaction mechanism with all products being connected by forward and backward reaction steps or by a reaction cycle. However, due to the elimination of oxygen atoms yielding $\mathrm{Pd}_{6} \mathrm{O}_{3}{ }^{+}, \mathrm{Pd}_{6} \mathrm{O}_{5}^{+}$, and $\mathrm{Pd}_{6} \mathrm{O}_{5}(\mathrm{CO})^{+}$which is only observed in the presence of $\mathrm{CO}$, and the fact that atomic oxygen (or potentially liberated $\mathrm{CO}_{2}$ ) is not present in the ion trap, an equilibrium reaction mechanism can be excluded. Thus, these products must be formed as part of a catalytic reaction cycle.

To gain more insight into the reaction mechanism the experiments have been repeated by exposing already preoxidized $\mathrm{Pd}_{6} \mathrm{O}^{+}$to an oxygen-rich $\mathrm{O}_{2} / \mathrm{CO}$ mixture. The result presented in Figure $4 \mathrm{c}$ shows a similar ion mass distribution as in the case of $\mathrm{Pd}_{6}{ }^{+}$showing the products $\mathrm{Pd}_{6} \mathrm{O}_{4}{ }^{+}, \mathrm{Pd}_{6} \mathrm{O}_{5}{ }^{+}$, and $\mathrm{Pd}_{6} \mathrm{O}_{5}(\mathrm{CO})^{+}$, although $\mathrm{Pd}_{6} \mathrm{O}_{3}{ }^{+}$has not been detected under these particular experimental conditions. The corresponding kinetic data in Figure $4 \mathrm{~d}$ reveal the fast formation of $\mathrm{Pd}_{6} \mathrm{O}_{5}{ }^{+}$, which is in agreement with oxidation studies that yield $\mathrm{Pd}_{6} \mathrm{O}_{5}{ }^{+}$ as the saturation product of the reaction between $\mathrm{Pd}_{6} \mathrm{O}^{+}$and $\mathrm{O}_{2}$ over a wide temperature range. ${ }^{36}$ The intensity of the $\mathrm{Pd}_{6} \mathrm{O}_{5}{ }^{+}$-signal then decreases and levels off at reaction times longer than $0.5 \mathrm{~s}$. In contrast, the intensity of $\mathrm{Pd}_{6} \mathrm{O}_{4}{ }^{+}$increases at $t_{\mathrm{R}}<0.5 \mathrm{~s}$, identifying $\mathrm{Pd}_{6} \mathrm{O}_{5}{ }^{+}$as a precursor of $\mathrm{Pd}_{6} \mathrm{O}_{4}^{+}$.

The simplest reaction mechanism that fits best the experimental data of $\mathrm{Pd}_{6}^{+}$and $\mathrm{Pd}_{6} \mathrm{O}^{+}$, and which accounts also for the results of the oxidation experiments, is shown in Figure 5. The fits of the integrated rate equations of this

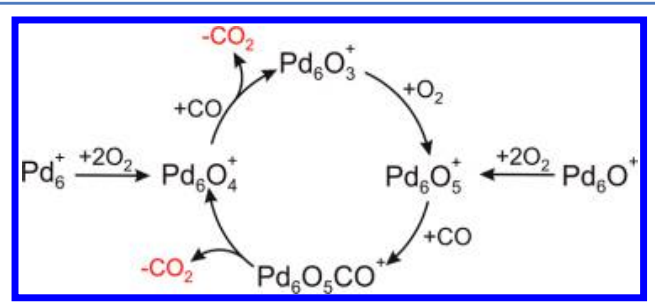

Figure 5. Proposed reaction mechanism that best fits the experimental data of $\mathrm{Pd}_{6}^{+}$and $\mathrm{Pd}_{6} \mathrm{O}^{+}$shown in Figure $4 \mathrm{~b}$,d.

mechanism to the experimental data are displayed in Figure $4 \mathrm{~b}, \mathrm{~d}$ as solid lines. In the following, the details of this catalytic reaction cycle will be discussed.

The dominance of the oxidation product $\mathrm{Pd}_{6} \mathrm{O}_{4}^{+}$in the reaction of $\mathrm{Pd}_{6}^{+}$with $\mathrm{O}_{2}$ and $\mathrm{CO}$ as well as the lack of products comprising only $\mathrm{CO}$ indicate the fast adsorption of two oxygen molecules as the first reaction steps. Because $\mathrm{Pd}_{6} \mathrm{O}_{4}{ }^{+}$was found to be oxidation resistant at room temperature, ${ }^{35 a}$ the product $\mathrm{Pd}_{6} \mathrm{O}_{5}{ }^{+}$cannot directly result from $\mathrm{Pd}_{6} \mathrm{O}_{4}{ }^{+}$, but instead, $\mathrm{Pd}_{6} \mathrm{O}_{3}{ }^{+}$ 


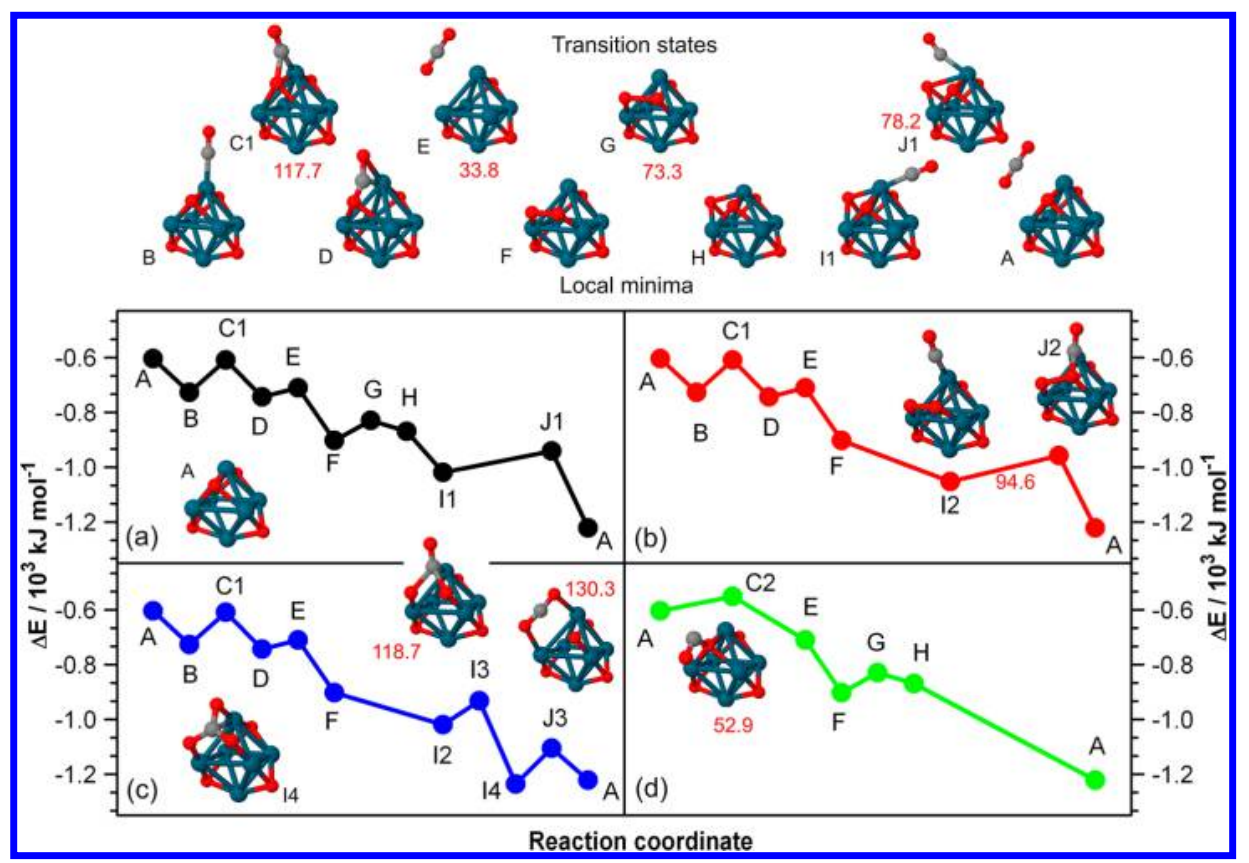

Figure 6. Calculated reaction pathways for the $\mathrm{Pd}_{6} \mathrm{O}_{4}{ }^{+}$-catalyzed oxidation of $\mathrm{CO} .{ }^{35 \mathrm{a}}$ Three different Langmuir-Hinshelwood mechanisms (with both reactants adsorbed on the catalyst) are given by (a) black, (b) red, and (c) blue symbols while an alternative Eley-Rideal mechanism (one reactant adsorbed and the other impinging from the gas phase, green symbols) is displayed in (d). Atomic configurations corresponding to the transition states and the local potential energy minima are shown above the graphs in the first and second row, respectively. The TS barrier energies are given in red next to the TS configurations (the desorption energy for the first $\mathrm{CO}_{2}$ molecule in black) in $\mathrm{kJ} \mathrm{mol}^{-1}$. $\mathrm{Pd}, \mathrm{O}^{2}$ and $\mathrm{C}$ atoms are represented by blue, red and gray spheres, respectively.

must be formed through the reaction with a first $\mathrm{CO}$ molecule and the formation and desorption of $\mathrm{CO}_{2}$ in the subsequent reaction step. $\mathrm{Pd}_{6} \mathrm{O}_{3}{ }^{+}$can then adsorb an additional $\mathrm{O}_{2}$ molecule yielding $\mathrm{Pd}_{6} \mathrm{O}_{5}{ }^{+}$. Due to the rather small intensity of the product $\mathrm{Pd}_{6} \mathrm{O}_{3}{ }^{+}$in the mass spectrum, it can be assumed that this reaction step proceeds at a fast rate. The next reaction step must then describe the interaction with a second $\mathrm{CO}$ molecule yielding $\mathrm{Pd}_{6} \mathrm{O}_{5} \mathrm{CO}^{+}$, which represents a precursor for the desorption of a second $\mathrm{CO}_{2}$ molecule that leads to the reformation of $\mathrm{Pd}_{6} \mathrm{O}_{4}^{+}$.

An identical catalytic reaction cycle can also be found for $\mathrm{Pd}_{6} \mathrm{O}^{+}$with the exception of the entrance channel. In both cases, that is, starting from $\mathrm{Pd}_{6}^{+}$or from $\mathrm{Pd}_{6} \mathrm{O}^{+}$, the first reaction steps are represented by the adsorption of two oxygen molecules yielding $\mathrm{Pd}_{6} \mathrm{O}_{4}^{+}$and $\mathrm{Pd}_{6} \mathrm{O}_{5}{ }^{+}$, respectively. The formation of different products in the entrance channel is evident from the kinetic data showing increased ion intensity of $\mathrm{Pd}_{6} \mathrm{O}_{5}^{+}$for the reaction of $\mathrm{Pd}_{6} \mathrm{O}^{+}$that decreases at longer reaction times, whereas for $\mathrm{Pd}_{6}^{+}$, the product $\mathrm{Pd}_{6} \mathrm{O}_{4}{ }^{+}$represents the main product in the whole investigated reaction time range.

Furthermore, from the reaction cycle (Figure 5), determined on the basis of the experimental data, it becomes clear that $\mathrm{Pd}_{6}{ }^{+}$ itself is not part of the catalytic cycle but that instead the nanooxide cluster $\mathrm{Pd}_{6} \mathrm{O}_{4}^{+}$is identified as the catalytically active reaction center. This experimental observation strongly supports the theoretical predictions that $\mathrm{CO}_{2}$ formation is most effective under reaction conditions where preformation of supported nano-oxide clusters $\mathrm{Pd}_{x} \mathrm{O}_{y} / \mathrm{MgO}$ is possible. ${ }^{21 \mathrm{c}, \mathrm{d}, 26} \mathrm{In}$ contrast, in previous $\mathrm{CO}$ oxidation experiments with platinum and gold clusters, the bare metal clusters $\mathrm{Pt}_{x}{ }^{ \pm}$and $\mathrm{Au}_{x}{ }^{-}$, respectively, were found to be part of the catalytic cycle instead of the corresponding oxides. ${ }^{53}$ Furthermore, the studies on $\mathrm{Pd}_{6}{ }^{+}$show that dissociatively adsorbed oxygen $\mathrm{O}(\mathrm{ad})$ represents an active species for $\mathrm{CO}$ oxidation, as has been found also on $\operatorname{Pd}(111)$ and $\operatorname{Pd}(100)$ surfaces. $^{8 b, 54}$ However, recent reactivity studies ${ }^{39}$ revealed that $\mathrm{CO}_{2}$ formation is not efficient enough on the mono-oxide $\mathrm{Pd}_{6} \mathrm{O}^{+}$, so that apparently the highly oxidized clusters, such as $\mathrm{Pd}_{6} \mathrm{O}_{4}{ }^{+}$or $\mathrm{Pd}_{6} \mathrm{O}_{5}{ }^{+}$, represent the more active catalytic species.

In comparison with $\mathrm{Pd}_{4}^{+}$and $\mathrm{Pd}_{5}^{+}$, the $\mathrm{Pd}_{6}^{+}$cluster is considerably more active in promoting the conversion of $\mathrm{CO}$ to $\mathrm{CO}_{2}$ under $\mathrm{O}_{2}$-rich pressure conditions. From the kinetics in Figure $4 \mathrm{~d}$, a catalytic turnover frequency (TOF) of $2.3 \pm 0.5$ $\mathrm{CO}_{2}$ molecules per second and per $\mathrm{Pd}_{6}^{+}$cluster can be determined, which is about one order of magnitude larger than the per-cluster TOF deduced for $\mathrm{Pd}_{4}{ }^{+}$above $\left(0.26 \pm 0.05 \mathrm{CO}_{2}\right.$ $\mathrm{s}^{-1}$ ). It is also interesting to compare these values (measured at $300 \mathrm{~K}$ ) to TOFs obtained by employing single crystal surfaces. For a $\mathrm{Pd}(111)$ surface, for example, a TOF of about $0.6 \mathrm{CO}_{2}$ $\mathrm{s}^{-1}$ per surface $\mathrm{Pd}$ atom site has been determined at $470 \mathrm{~K}$ and $p(\mathrm{CO})=133 \mathrm{~Pa}, p\left(\mathrm{O}_{2}\right)=67 \mathrm{~Pa}^{4}$ In these experiments, the TOF was found to decrease linearly with the oxygen pressure and to depend on the temperature in an Arrhenius-type relation in the investigated temperature range ( 470 to $570 \mathrm{~K}$ ).

The major reasons for the apparently superior performance of the $\mathrm{Pd}_{6}^{+}$nanocatalyst can be found in the high reactivity toward $\mathrm{O}_{2}$, which leads to the facile formation of stable $\mathrm{Pd}_{6} \mathrm{O}_{y}^{+}$ complexes, ${ }^{35 a, 36}$ in combination with a rather small $\mathrm{CO}$ binding energy to $\mathrm{Pd}_{6}^{+}\left(103.3 \mathrm{~kJ} \mathrm{~mol}^{-140 \mathrm{~h}}\right)$ that leads to a rate constant for CO desorption $\left(k_{-1}=1.1 \mathrm{~s}^{-1}\right)$ at room temperature, which is several orders of magnitude larger than for $\operatorname{Pd}_{4}^{+}\left(k_{-1}=2.6 \times\right.$ $\left.10^{-7} \mathrm{~s}^{-1}\right), \mathrm{Pd}_{5}^{+}\left(k_{-1}=6.5 \times 10^{-5} \mathrm{~s}^{-1}\right)$, and also for extended palladium surfaces $\left(k_{-1}=10^{-9}-10^{-12} \mathrm{~s}^{-16 \mathrm{~b}, \mathrm{c}}\right)$.

Reaction Energetics. To gain more detailed insight into the energetics of the catalytic CO combustion reaction mediated by $\mathrm{Pd}_{6} \mathrm{O}_{4}{ }^{+}$and to allow for a quantitative comparison with the previous studies on extended Pd surfaces and on supported Pd nanoparticles, first-principles DFT calculations have been 
performed. Figure 6 displays four different possible reaction pathways along with the atomic configurations that correspond to the transition state barriers and local potential energy minima.

The first reaction mechanism (Figure 6a) follows a Langmuir-Hinshelwood scheme where the reaction occurs through interaction of adsorbed molecules and atoms. The sequence of steps starts with the barrier-free adsorption of a first $\mathrm{CO}$ molecule on the tetroxide cluster $\mathrm{Pd}_{6} \mathrm{O}_{4}{ }^{+}$(configuration A) yielding $\mathrm{Pd}_{6} \mathrm{O}_{4} \mathrm{CO}^{+}$(configuration $\mathrm{B}$, $\mathrm{CO}$ binding energy $\left.E(\mathrm{CO})=122.6 \mathrm{~kJ} \mathrm{~mol}^{-1}\right)$. The adsorbed $\mathrm{CO}$ molecule reacts with an oxygen atom of $\mathrm{Pd}_{6} \mathrm{O}_{4}{ }^{+}$(activation barrier $E_{\mathrm{b}}=$ $117.7 \mathrm{~kJ} \mathrm{~mol}^{-1}$, configuration $\mathrm{C} 1$ ) which results in the complex D. $\mathrm{CO}_{2}$ is formed in this reaction step on the cluster in a bent configuration with an $\mathrm{O}-\mathrm{C}-\mathrm{O}$ angle of about $113^{\circ}$ in the transition state $\mathrm{C} 1$. Subsequent reaction steps then involve the desorption of the formed $\mathrm{CO}_{2}$ molecule yielding $\mathrm{Pd}_{6} \mathrm{O}_{3}{ }^{+}$ (configuration $\mathrm{E}, \mathrm{E}\left(\mathrm{CO}_{2}\right)=33.8 \mathrm{~kJ} \mathrm{~mol}^{-1}$ ), and the adsorption of an oxygen molecule resulting in $\mathrm{Pd}_{6} \mathrm{O}_{5}{ }^{+}$(configuration $\mathrm{F}$, $\left.E\left(\mathrm{O}_{2}\right)=192.1 \mathrm{~kJ} \mathrm{~mol}^{-1}, \mathrm{~d}(\mathrm{O}-\mathrm{O})=1.38 \AA\right)$. This activated $\mathrm{O}_{2}$ molecule $(\mathrm{d}(\mathrm{O}-\mathrm{O})$ is larger by $0.13 \AA$ compared to the bond length in the gaseous $\mathrm{O}_{2}$ molecule) dissociates in an activated process $\left(E_{\mathrm{b}}=73.3 \mathrm{~kJ} \mathrm{~mol}^{-1}\right.$, configurations $\mathrm{F} \rightarrow \mathrm{G} \rightarrow \mathrm{H}, d(\mathrm{O}-$ $\mathrm{O})=2.8 \AA$ in $\mathrm{H}$ ) before the barrier-free adsorption of a second $\mathrm{CO}$ molecule $\left(E(\mathrm{CO})=150.6 \mathrm{~kJ} \mathrm{~mol}^{-1}\right)$, yielding the experimentally observed complex $\mathrm{Pd}_{6} \mathrm{O}_{5} \mathrm{CO}^{+}$(configuration I1). $\mathrm{CO}_{2}$ is formed on the cluster via the transition state $\mathrm{J} 1$. Here the adsorbed $\mathrm{CO}_{2}$ has a bent geometry comparable to the preceding reaction step $\left(\mathrm{O}-\mathrm{C}-\mathrm{O}\right.$ angle: $\left.126^{\circ}\right)$. The catalytic cycle is closed by reformation of $\mathrm{Pd}_{6} \mathrm{O}_{4}^{+}$(configuration $\mathrm{A}$ ) and $\mathrm{CO}_{2}$ liberation involving an activation barrier of $E_{\mathrm{b}}=78.2 \mathrm{~kJ}$ $\mathrm{mol}^{-1}$ (configurations $\mathrm{I} 1 \rightarrow \mathrm{J} 1 \rightarrow \mathrm{A}$ ). The energy released in this last reaction step amounts to $203 \mathrm{~kJ} \mathrm{~mol}^{-1}$ and will initially lead to a vibrational excitation of the $\mathrm{Pd}_{6} \mathrm{O}_{4}{ }^{+}$cluster and also to an excitation of the desorbing $\mathrm{CO}_{2}$ before thermalization in the buffer gas. Consistent with the experimentally proposed mechanism (Figure 5), the calculations also show that structure $\mathrm{H}$ can be formed also in the reaction of $\mathrm{Pd}_{6} \mathrm{O}^{+}$with two $\mathrm{O}_{2}$ molecules.

Two alternative pathways, also following a LangmuirHinshelwood reaction mechanism, are displayed in Figure 6 b,c. In both cases, the first reaction steps starting from $\mathrm{Pd}_{6} \mathrm{O}_{4}{ }^{+}$ (configuration A) and resulting in $\mathrm{Pd}_{6} \mathrm{O}_{5}^{+}$(configuration $\mathrm{F}$ ) are identical to the pathway in Figure 6a. However, in the pathway presented in Figure $6 \mathrm{~b}$, the molecularly adsorbed $\mathrm{O}_{2}$ does not dissociate on the cluster, but instead, $\mathrm{CO}$ is directly adsorbed on configuration $\mathrm{F}\left(E(\mathrm{CO})=150.6 \mathrm{~kJ} \mathrm{~mol}^{-1}\right)$ leading to barrier-free formation of $\mathrm{I} 2$. Subsequent reaction of $\mathrm{CO}$ with an oxygen atom and desorption of $\mathrm{CO}_{2}$ involves an activation barrier of $E_{\mathrm{b}}=94.6 \mathrm{~kJ} \mathrm{~mol}^{-1}$ (configurations I2 $\rightarrow \mathrm{J} 2 \rightarrow \mathrm{A}$ ). The pathway in Figure $6 \mathrm{c}$ is identical to the previous one until the formation of I2. Then it proceeds via the activated formation of an intermediate I4 (configurations I2 $\rightarrow \mathrm{I} 3 \rightarrow \mathrm{I} 4$, $E_{\mathrm{b}}=118.7 \mathrm{~kJ} \mathrm{~mol}^{-1}$ ) containing a partially negatively charged $(\delta=0.7 \mathrm{e}) \mathrm{CO}_{3}^{-\delta}$ unit, as well as the activated formation and desorption of $\mathrm{CO}_{2}$ (configurations $\mathrm{I} 4 \rightarrow \mathrm{J} 3 \rightarrow \mathrm{A}, E_{\mathrm{b}}=130.3 \mathrm{~kJ}$ $\mathrm{mol}^{-1}$ ). Interestingly, in the transition state $\mathrm{J} 3$ just before desorption, the $\mathrm{CO}_{2}$ molecule exhibits an almost linear geometry in contrast to the transition states discussed above.

Finally, Figure $6 \mathrm{~d}$ displays an alternative reaction pathway following an Eley-Rideal mechanism where the reaction occurs between an impinging gas phase molecule and an adsorbed species. According to this Eley-Rideal reaction mechanism, the
$\mathrm{CO}$ molecule directly adsorbs on an oxygen atom of $\mathrm{Pd}_{6} \mathrm{O}_{4}{ }^{+}$ (configuration A) and leads to the formation (in a strongly bent transition state geometry) and desorption of a first $\mathrm{CO}_{2}$ molecule, which involves a small activation barrier of $E_{\mathrm{b}}=$ $52.9 \mathrm{~kJ} \mathrm{~mol}^{-1}$ (configuration $\mathrm{C} 2$ ) and results in $\mathrm{Pd}_{6} \mathrm{O}_{3}{ }^{+}$ (configuration E). This oxide adsorbs another $\mathrm{O}_{2}$ molecule (configuration $\mathrm{F}$ ) and undergoes activated structural rearrangement (configuration $\mathrm{G}, E_{\mathrm{b}}=73.3 \mathrm{~kJ} \mathrm{~mol}^{-1}$ ), yielding configuration $\mathrm{H}$, as already observed in the LangmuirHinshelwood pathway in Figure 6a. The subsequent adsorption of a second $\mathrm{CO}$ molecule and the formation and liberation of $\mathrm{CO}_{2}$ is barrier-free.

Thus, these predicted reaction pathways demonstrate that the occurrence of effective room-temperature oxidation of $\mathrm{CO}$ with molecular oxygen promoted by $\mathrm{Pd}_{6} \mathrm{O}_{4}^{+}$is possible, and they are completely consistent with the reaction mechanism determined on the basis of the experimental reaction kinetics data for $\mathrm{Pd}_{6}^{+}$and $\mathrm{Pd}_{6} \mathrm{O}^{+}$(cf. Figure 5 and the discussion in section Room-Temperature CO Oxidation).

Comparison with Pd Surfaces. Figure 7a displays a schematic potential diagram illustrating the energetics of the

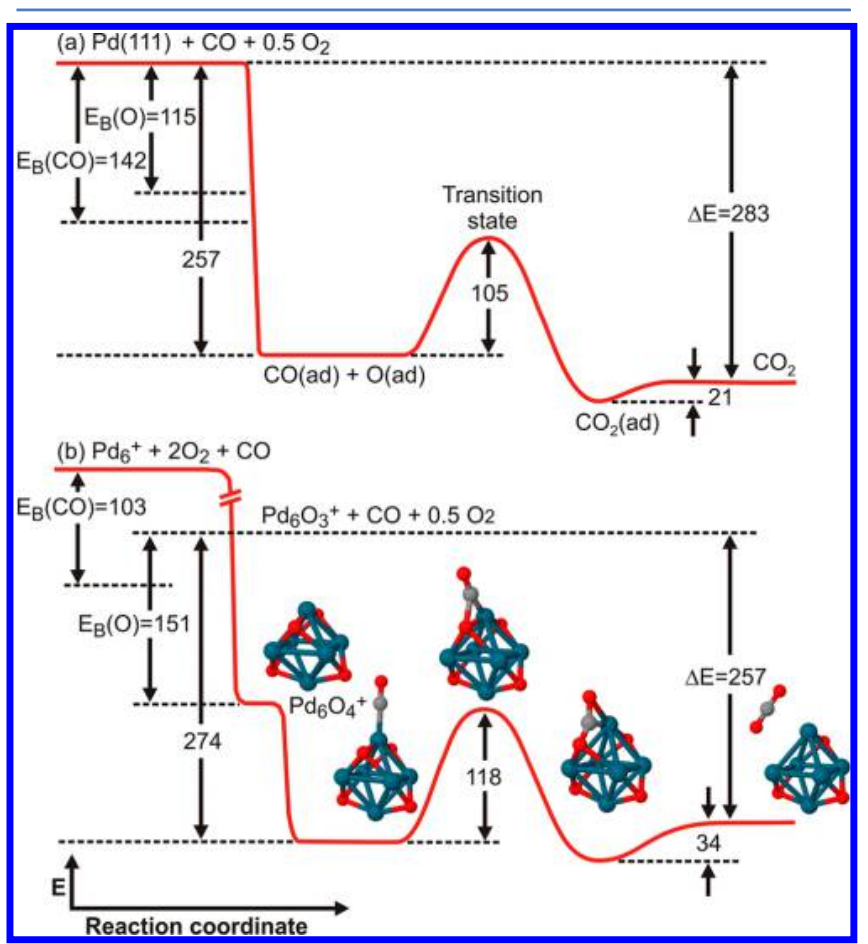

Figure 7. Schematic potential diagrams (energies in $\mathrm{kJ} \mathrm{mol}^{-1}$ ) for the $\mathrm{CO}$ oxidation on (a) a Pd(111) single crystal at low coverages ${ }^{3 \mathrm{~b}, 55}$ and (b) the $\mathrm{Pd}_{6} \mathrm{O}_{4}{ }^{+}$cluster. The diagram for $\mathrm{Pd}(111)$ has been constructed from quantitative experimental data, and the energies in the diagram for the palladium cluster have been obtained by theoretical simulations and correspond to the reaction steps which are associated with the structures A-E in Figure $6 a-c$.

$\mathrm{CO}$ oxidation reaction on a $\mathrm{Pd}(111)$ surface at low $\mathrm{O}_{2}$ and $\mathrm{CO}$ coverages (corresponding to a temperature range of 500-700 $\mathrm{K})$, which has been constructed by Ertl and co-workers on the basis of quantitative experimental data. ${ }^{3 \mathrm{~b}, 55}$ Chemisorption of $\mathrm{CO}+1 / 2 \mathrm{O}_{2}$ results in the liberation of an energy of about 257 $\mathrm{kJ} \mathrm{mol}^{-1}\left(E_{\mathrm{b}}(\mathrm{CO})=142 \pm 4 \mathrm{~kJ} \mathrm{~mol}^{-16 \mathrm{~b}, 55}\right.$ and $E_{\mathrm{b}}(\mathrm{O})=115 \mathrm{~kJ}$ $\mathrm{mol}^{-1}$; note that oxygen will experience recombinative molecular desorption at higher temperatures than $\mathrm{CO}$ ), ${ }^{56}$ which is dissipated in the solid. The formation of a carbon 
dioxide molecule on the surface, $\mathrm{CO}_{2}(\mathrm{ad})$, from the adsorbed $\mathrm{CO}(\mathrm{ad})$ and $\mathrm{O}(\mathrm{ad})$ represents an activated LangmuirHinshelwood process involving a barrier of $105 \pm 8 \mathrm{~kJ}$ $\mathrm{mol}^{-1}$, whereas the final liberation of $\mathrm{CO}_{2}$ is only slightly activated by $21 \mathrm{~kJ} \mathrm{~mol}^{-1}$. $\mathrm{b}, 55$

The overall reaction $\mathrm{CO}+1 / 2 \mathrm{O}_{2} \rightarrow \mathrm{CO}_{2}$ is exothermic with a total energy gain of $283 \mathrm{~kJ} \mathrm{~mol}^{-1}$. $3 \mathrm{~b}, 55$ Nevertheless, a reaction temperature of at least about $450 \mathrm{~K}$ is required to enable $\mathrm{CO}_{2}$ formation. ${ }^{3 \mathrm{~b}}$ The reasons for these high temperatures are, as discussed in section 1.1, not found in the height of the activation barriers but rather in the strong binding of $\mathrm{CO}$ to palladium, which leads to $\mathrm{CO}$ poisoning of the surface at lower temperatures (in particular at elevated $\mathrm{CO}$ pressures) and thus inhibits $\mathrm{O}_{2}$ coadsorption and consequently a quenching of the reaction.

A comparable potential diagram for the $\mathrm{CO}$ combustion reaction mediated by the free nano-oxide $\mathrm{Pd}_{6} \mathrm{O}_{4}{ }^{+}$is shown in Figure $7 \mathrm{~b}$. The energies and atomic structures displayed in this figure are equivalent to the theoretically obtained transition states and local minima A to E of Figure 6. For a direct comparison with the energetics on a $\operatorname{Pd}(111)$ surface, the sum of the average binding energy of one oxygen atom in $\mathrm{Pd}_{6} \mathrm{O}_{4}{ }^{+}$ $\left(151 \mathrm{~kJ} \mathrm{~mol}^{-135 a}\right.$ ) and the binding energy of a first $\mathrm{CO}$ molecule to $\mathrm{Pd}_{6} \mathrm{O}_{4}^{+}\left(123 \mathrm{~kJ} \mathrm{~mol}^{-1}\right)$ are given, resulting in a total energy of $274 \mathrm{~kJ} \mathrm{~mol}^{-1}$ for the formation of configuration B. This energy gain is only slightly larger than the energy gained upon adsorption of $\mathrm{CO}$ and $1 / 2 \mathrm{O}_{2}$ onto a $\mathrm{Pd}(111)$ surface. Configuration $\mathrm{B}$ then transforms into configuration $\mathrm{D}$ in a process that entails an activation barrier of $118 \mathrm{~kJ} \mathrm{~mol}^{-1}$ (configuration $\mathrm{C1}$ ). This barrier is equivalent to the LangmuirHinshelwood barrier shown in Figure 7a.

The calculated activation energy for the analogous reaction of an adsorbed $\mathrm{CO}$ molecule with one oxygen atom of $\mathrm{Pd}_{6} \mathrm{O}_{5}{ }^{+}$ amounts to $78 \mathrm{~kJ} \mathrm{~mol}^{-1}$ (transition state $\mathrm{J} 1$ in Figure $6 \mathrm{a}$ ) or $94.6 \mathrm{~kJ} \mathrm{~mol}^{-1}$ (transition state J2), respectively. Thus, the type of adsorbed oxygen atoms decisively influences the activation energy of $\mathrm{CO}_{2}$ formation. This is very much in line with UHV surface studies (see, e.g., introductory review in ref 57): The "classical" Langmuir-Hinshelwood activation energy of this reaction determined by Ertl and co-workers ${ }^{3 \mathrm{~b}, 55}$ amounts to $105 \mathrm{~kJ} \mathrm{~mol}^{-1}$ at low $\mathrm{CO}$ pressures and reduces to $59 \mathrm{~kJ} \mathrm{~mol}^{-1}$ at moderate $\mathrm{CO}$ pressures due to a rearrangement of the oxygen adlayer. Varying activation energies for the $\mathrm{CO}$ combustion reaction with varying oxygen adsorption geometry have also been observed by other authors. ${ }^{58}$ Subsequent desorption of the formed $\mathrm{CO}_{2}$ molecule involves a second activation barrier of $34 \mathrm{~kJ} \mathrm{~mol}^{-1}$, which is also very close to the experimental value of $21 \mathrm{~kJ} \mathrm{~mol}^{-1}$ obtained on a $\operatorname{Pd}(111)$ surface.

From Figure 7, it is thus apparent that the overall energetics of the $\mathrm{CO}$ oxidation reaction catalyzed by a $\mathrm{Pd}(111)$ surface and that on the $\mathrm{Pd}_{6} \mathrm{O}_{4}{ }^{+}$cluster, respectively, exhibit some remarkable similarities while also displaying fundamental differences like, for example, the oxide cluster being the active catalyst in the present case. One further important difference between these two catalytic systems is the binding behavior of carbon monoxide, and this difference determines that, in the case of $\mathrm{Pd}_{6} \mathrm{O}_{4}{ }^{+}$, the catalytic $\mathrm{CO}$ combustion is possible already at room temperature (and below, see next section), whereas for the Pd surface, at least a temperature of $450 \mathrm{~K}$ is required for the reaction to proceed.

The $\mathrm{CO}$ bond strength to a $\operatorname{Pd}(111)$ surface is largely independent (at low coverages) of whether oxygen is already present on the surface or not. In addition, the value of the CO binding energy $\left(142 \mathrm{~kJ} \mathrm{~mol}^{-1}\right)$ clearly exceeds the binding energy of oxygen atoms, which amounts to $115 \mathrm{~kJ} \mathrm{~mol}^{-1}$. In contrast, the $\mathrm{CO}$ binding energy to a bare $\mathrm{Pd}_{6}{ }^{+}$cluster is only $103 \mathrm{~kJ} \mathrm{~mol}^{-1}$, ${ }^{0 \mathrm{~h}}$ hence, considerably less than the enhanced binding of the oxygen atoms in $\mathrm{Pd}_{6} \mathrm{O}_{4}{ }^{+}$of $151 \mathrm{~kJ} \mathrm{~mol}^{-1}$. This low $\mathrm{CO}$ binding energy determines the desorption rate of $\mathrm{CO}$ from $\mathrm{Pd}_{6}{ }^{+}$(as shown in Figure 1) and, thus, the temperature for effective $\mathrm{CO}_{2}$ formation. Once the nano-oxide $\mathrm{Pd}_{6} \mathrm{O}_{4}^{+}$is formed, the $\mathrm{CO}$ binding energy is increased to $123 \mathrm{~kJ} \mathrm{~mol}^{-1}$, which, however, does not affect the facile $\mathrm{CO}_{2}$ formation.

Although the Langmuir-Hinshelwood barrier for $\mathrm{CO}_{2}$ formation is slightly higher and the overall energy gain of the reaction is smaller on the free $\mathrm{Pd}_{6} \mathrm{O}_{4}{ }^{+}$compared to a $\mathrm{Pd}(111)$ surface, the considerably reduced $\mathrm{CO}$ binding energy on the bare $\mathrm{Pd}_{6}^{+}$results in a large desorption rate, protecting the cluster from $\mathrm{CO}$ poisoning and facilitating $\mathrm{O}_{2}$ coadsorption at considerably lower temperatures. For comparison, the $\mathrm{CO}$ desorption rate constant from $\mathrm{Pd}_{6} \mathrm{CO}^{+}$, at $300 \mathrm{~K}$, is $k_{-1} \sim 1 \mathrm{~s}^{-1}$ $\left(=k_{\mathrm{e}}=4.4 \times 10^{-15} \mathrm{~cm}^{3} \mathrm{~s}^{-1}\right.$ assuming $p(\mathrm{He})=1 \mathrm{~Pa}$, cf. Figure 1b). Due to the high CO binding energy of $142 \mathrm{~kJ} \mathrm{~mol}^{-1}$ on a $\operatorname{Pd}(111)$ single crystal, ${ }^{6 \mathrm{~b}}$ similar rate constants can only be achieved at about $515 \mathrm{~K}$. At this temperature, $\mathrm{CO}$ oxidation has been observed to occur. ${ }^{3 \mathrm{~b}}$

Temperature Dependence. In the above, it has been demonstrated that the oxidation of $\mathrm{CO}$ by molecular oxygen catalyzed by $\mathrm{Pd}_{6} \mathrm{O}_{4}{ }^{+}$, takes place even at room temperature. In order to evaluate the range in which low temperature catalytic conversion is possible, temperature-dependent measurements have been performed by cooling the ion trap in steps of $20 \mathrm{~K}$ down to cryogenic temperatures. At each temperature, product ion mass spectra were recorded after the reaction of $\mathrm{Pd}_{6} \mathrm{O}^{+}$with $\mathrm{O}_{2}$ and $\mathrm{CO}$ for $t_{\mathrm{R}}=0.1 \mathrm{~s}$ in the ion trap. The results of these experiments are shown in Figure 8 in a $2 \mathrm{D}$ contour plot representation.

Under the given experimental conditions, the products $\mathrm{Pd}_{6} \mathrm{O}_{3}{ }^{+}, \mathrm{Pd}_{6} \mathrm{O}_{4}^{+}, \mathrm{Pd}_{6} \mathrm{O}_{5}^{+}$, and $\mathrm{Pd}_{6} \mathrm{O}_{5} \mathrm{CO}^{+}$are observed in the mass spectrum at room temperature. This ion mass distribution remains unchanged upon cooling the ion trap down to about

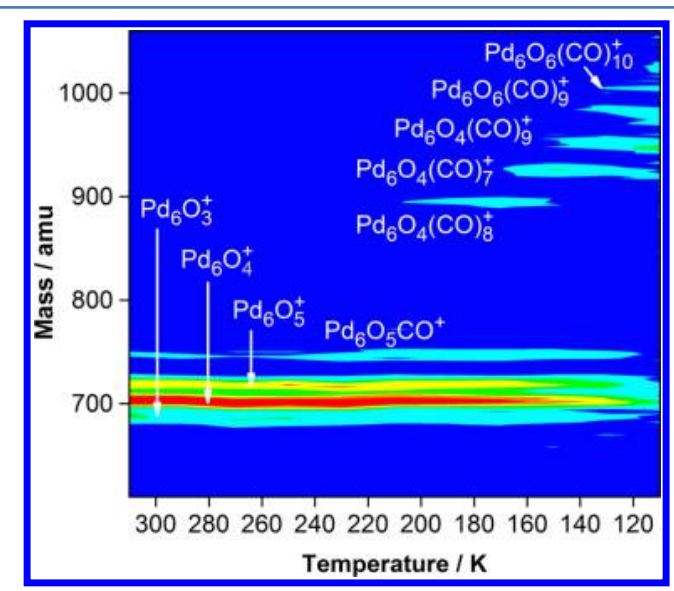

Figure 8. Two-dimensional contour plot representation of the temperature-dependent reaction of $\mathrm{Pd}_{6} \mathrm{O}^{+}$with $\mathrm{O}_{2}$ and $\mathrm{CO}$ (recorded in steps of $20 \mathrm{~K}, t_{\mathrm{R}}=0.1 \mathrm{~s}$ ), illustrating the effective $\mathrm{CO}$ oxidation reaction over a wide temperature range between $300 \mathrm{~K}$ and about 190 K. $p\left(\mathrm{O}_{2}\right)=0.070 \mathrm{~Pa}, p(\mathrm{CO})=0.006 \mathrm{~Pa}$. Displayed are mass spectra as a function of temperature. The relative intensity of the mass signals is color coded ranging from blue $(0 \%)$ to red $(100 \%)$. 
$190 \mathrm{~K}$. However, below this temperature, the intensities of the room-temperature products decrease while new products appear. The recorded mass signals correspond to $\mathrm{Pd}_{6} \mathrm{O}_{4}(\mathrm{CO})_{7}{ }^{+}, \mathrm{Pd}_{6} \mathrm{O}_{4}(\mathrm{CO})_{8}{ }^{+}, \mathrm{Pd}_{6} \mathrm{O}_{4}(\mathrm{CO})_{9}{ }^{+}, \mathrm{Pd}_{6} \mathrm{O}_{6}(\mathrm{CO})_{9}{ }^{+}$, and $\mathrm{Pd}_{6} \mathrm{O}_{6}(\mathrm{CO})_{10}{ }^{+}$. These products indicate that the $\mathrm{CO}$ adsorption is enhanced at very low temperatures and that apparently the $\mathrm{CO}$ oxidation is hindered accordingly at temperatures below $190 \mathrm{~K}$.

These temperature-dependent ion mass distributions demonstrate that the catalytic CO oxidation is indeed possible at temperatures well below room temperature. However, the mass spectra also indicate the formation of CO-rich complexes $\mathrm{Pd}_{6} \mathrm{O}_{y}(\mathrm{CO})_{z}^{+}(y=4,6, z=7-10)$ and thus the poisoning of the cluster by $\mathrm{CO}$ at temperatures below $190 \mathrm{~K}$. This observation reflects a marked decrease of the rate constant for CO desorption (reduction of 6 orders of magnitude for 200 $\mathrm{K}$ compared to $300 \mathrm{~K}$ ), which results in the formation of the complexes with multiple $\mathrm{CO}$ molecules.

Catalyst Poisoning versus Cooperative Effects. In section Room-Temperature CO Oxidation, it has been shown that an appropriate choice of the $\mathrm{O}_{2} / \mathrm{CO}$ pressure ratio can compensate for differences in the termolecular $\mathrm{CO}$ and $\mathrm{O}_{2}$ adsorption rate constants on $\mathrm{Pd}_{6}{ }^{+}$(Table 1) and thus enable effective $\mathrm{CO}$ oxidation. However, the temperature-dependent experiments already indicated the possibility of $\mathrm{CO}$ poisoning of the $\mathrm{Pd}_{6}{ }^{+}$cluster at temperatures below $190 \mathrm{~K}$. For further insight into a potential catalyst poisoning, we studied next the reaction of $\mathrm{Pd}_{6}^{+}$with different $\mathrm{O}_{2} / \mathrm{CO}$ mixtures at room temperature. Figure 9a,b display ion mass spectra and kinetic data obtained under $\mathrm{O}_{2}$-rich conditions yielding the products $\mathrm{Pd}_{6} \mathrm{O}_{3}{ }^{+}, \mathrm{Pd}_{6} \mathrm{O}_{4}{ }^{+}, \mathrm{Pd}_{6} \mathrm{O}_{5}{ }^{+}$, and $\mathrm{Pd}_{6} \mathrm{O}_{5} \mathrm{CO}^{+}$, as already shown in

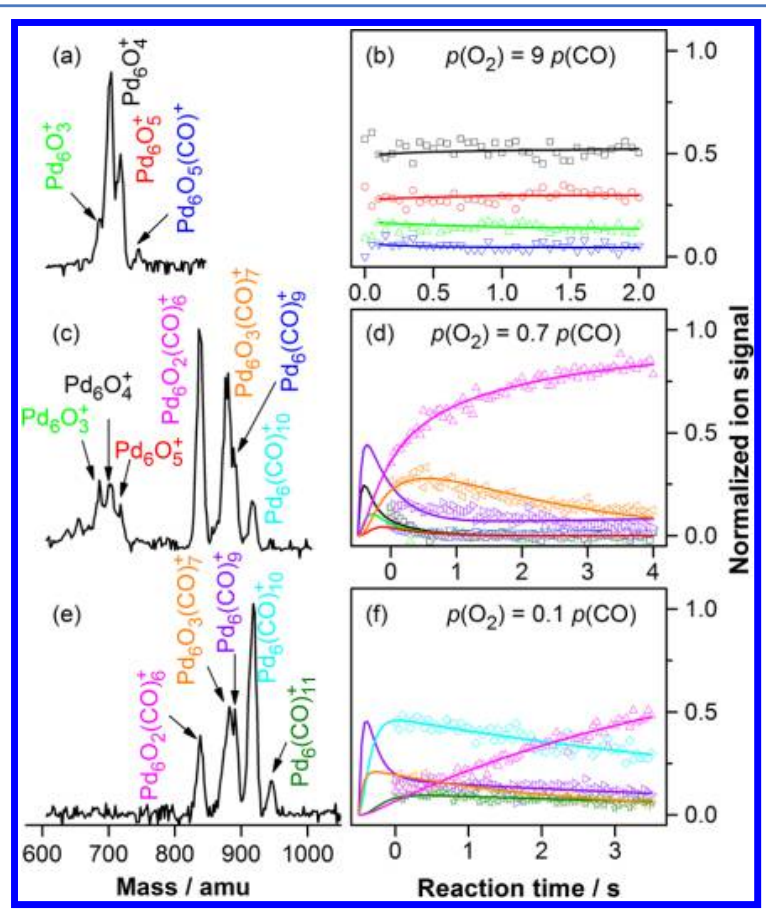

Figure 9. Pressure-dependent product ion mass distributions and corresponding kinetic data for the reaction of $\mathrm{Pd}_{6}{ }^{+}$with $\mathrm{O}_{2}$ and $\mathrm{CO}$ at room temperature showing the change from effective $\mathrm{CO}$ combustion under $\mathrm{O}_{2}$-rich conditions to $\mathrm{CO}$ poisoning with increasing $\mathrm{CO}$ concentration. $(\mathrm{a}, \mathrm{b}): p\left(\mathrm{O}_{2}\right)=9 p(\mathrm{CO})\left(p\left(\mathrm{O}_{2}\right)=0.09 \mathrm{~Pa}, p(\mathrm{CO})=\right.$ $0.01 \mathrm{~Pa}),(\mathrm{c}, \mathrm{d}): p\left(\mathrm{O}_{2}\right)=0.7 p(\mathrm{CO})\left(p\left(\mathrm{O}_{2}\right)=0.010 \mathrm{~Pa}, p(\mathrm{CO})=0.015\right.$ $\mathrm{Pa}) ;(\mathrm{e}, \mathrm{f}): p\left(\mathrm{O}_{2}\right)=0.1 p(\mathrm{CO})\left(p\left(\mathrm{O}_{2}\right)=0.01 \mathrm{~Pa}, p(\mathrm{CO})=0.10 \mathrm{~Pa}\right)$.
Figure 4a,b and discussed in section Room-Temperature $\mathrm{CO}$ Oxidation. Decreasing the relative $\mathrm{O}_{2}$ partial pressure $\left(p\left(\mathrm{O}_{2}\right)=\right.$ $0.7 p(\mathrm{CO})$, Figure $9 \mathrm{c}, \mathrm{d})$ leads to a decrease in the intensity of these products while additional new complexes $\mathrm{Pd}_{6} \mathrm{O}_{2}(\mathrm{CO})_{6}{ }^{+}$, $\mathrm{Pd}_{6} \mathrm{O}_{3}(\mathrm{CO})_{7}^{+}$, as well as products comprising $\mathrm{CO}$ molecules only, $\mathrm{Pd}_{6}(\mathrm{CO})_{9}{ }^{+}$and $\mathrm{Pd}_{6}(\mathrm{CO})_{10}{ }^{+}$, appear. The corresponding kinetics show fast formation of $\mathrm{Pd}_{6} \mathrm{O}_{4}^{+}$and $\mathrm{Pd}_{6}(\mathrm{CO})_{9}^{+}$, indicating a competition between $\mathrm{O}_{2}$ and $\mathrm{CO}$ adsorption under these pressure conditions and thus a competition between $\mathrm{CO}$ combustion and $\mathrm{CO}$ poisoning. Furthermore, $\mathrm{Pd}_{6} \mathrm{O}_{4}^{+}$and $\mathrm{Pd}_{6}(\mathrm{CO})_{9}{ }^{+}$are precursors for the remaining products with $\mathrm{Pd}_{6} \mathrm{O}_{2}(\mathrm{CO})_{6}^{+}$representing the stable final product. Most importantly, in contrast to the kinetic traces shown in Figure 9b, no equilibrium kinetics are observed anymore, which means that the potential catalytic $\mathrm{CO}_{2}$ formation terminates because of the formation of the final product $\mathrm{Pd}_{6} \mathrm{O}_{2}(\mathrm{CO})_{6}{ }^{+}$.

A further decrease in the $\mathrm{O}_{2} / \mathrm{CO}$ pressure ratio $\left(p\left(\mathrm{O}_{2}\right)=0.1\right.$ $p(\mathrm{CO})$, Figure $9 \mathrm{e}, \mathrm{f})$ leads to a complete shift in the ion mass distribution to the $\mathrm{CO}$-rich products $\mathrm{Pd}_{6} \mathrm{O}_{2}(\mathrm{CO})_{6}{ }^{+}$, $\mathrm{Pd}_{6} \mathrm{O}_{3}(\mathrm{CO})_{7}{ }^{+}, \mathrm{Pd}_{6}(\mathrm{CO})_{9}{ }^{+}, \mathrm{Pd}_{6}(\mathrm{CO})_{10}{ }^{+}$, and $\mathrm{Pd}_{6}(\mathrm{CO})_{11}{ }^{+}$, whereas $\mathrm{Pd}_{6} \mathrm{O}_{3}{ }^{+}, \mathrm{Pd}_{6} \mathrm{O}_{4}{ }^{+}$, and $\mathrm{Pd}_{6} \mathrm{O}_{5}{ }^{+}$do not appear anymore in the mass spectrum. Under these $\mathrm{CO}$-rich conditions, oxide formation is hampered, and the adsorption of $\mathrm{CO}$ is dominating the reaction. This results in the fast formation of $\mathrm{Pd}_{6}(\mathrm{CO})_{9}^{+}$(faster than the time-scale of the experiment), which represents the precursor for all other products. However, in contrast to extended Pd single-crystal surfaces, which are completely poisoned by $\mathrm{CO}$ under $\mathrm{CO}$-rich conditions by site blocking for oxygen adsorption, the complex $\mathrm{Pd}_{6}(\mathrm{CO})_{9}{ }^{+}$does not represent the final product. Instead, it serves as a precursor for the oxygen-containing complexes $\mathrm{Pd}_{6} \mathrm{O}_{2}(\mathrm{CO})_{6}{ }^{+}$and $\mathrm{Pd}_{6} \mathrm{O}_{3}(\mathrm{CO})_{7}^{+}$, as can be seen from the kinetic data in Figure 9f. This finding is in agreement with previous studies on small deposited $\mathrm{Pd}_{x}$ clusters for which preadsorbed $\mathrm{CO}$ was observed to promote oxygen adsorption and dissociation. ${ }^{21 \mathrm{~b}}$ Consequently, $\mathrm{CO}$ does not completely poison the small $\mathrm{Pd}_{6}^{+}$ clusters; however, it can be concluded that $\mathrm{CO}$ oxidation is not effective anymore under CO-rich pressure conditions and the catalytic cycle terminates through formation of the final product $\mathrm{Pd}_{6} \mathrm{O}_{2}(\mathrm{CO})_{6}^{+}$.

\section{CONCLUSION}

In this paper, we reported on the comprehensive experimental and theoretical investigations of the catalytic low-temperature $\mathrm{CO}$ combustion reaction mediated by small free palladium clusters $\mathrm{Pd}_{x}^{+}(x=2-7)$ and their oxides $\mathrm{Pd}_{x} \mathrm{O}^{+}(x=2-7)$. Utilizing ion trap mass spectrometry in conjunction with firstprinciples computations, we focused mainly on the clusters $\mathrm{Pd}_{4}^{+}, \mathrm{Pd}_{5}^{+}$, and $\mathrm{Pd}_{6}^{+}$and their oxides as model systems for studies of the kinetics and energetics of the catalytic $\mathrm{CO}$ oxidation reaction. The findings were interpreted on the basis of $\mathrm{CO}$ and $\mathrm{O}_{2}$ adsorption and desorption rate constants and compared with previous investigations on $\mathrm{Pd}$ single-crystal surfaces as well as supported nanoparticles and small clusters.

For all investigated cluster sizes, the fast $\mathrm{O}_{2}$ adsorption and dissociation and the $\mathrm{CO}$ binding strength were found to be the key factors that determine the effective CO oxidation. This is in agreement with previous studies on Pd single crystals and supported nanoparticles and clusters.

Strong $\mathrm{CO}$ binding to $\mathrm{Pd}_{4}^{+}$and $\mathrm{Pd}_{5}{ }^{+}$inhibits effective lowtemperature $\mathrm{CO}_{2}$ formation even under oxygen-rich reaction conditions, whereas $\mathrm{Pd}_{6}^{+}$was identified as being particularly 
active in catalyzing this reaction in a temperature range between 300 and $190 \mathrm{~K}$ under $\mathrm{O}_{2}$-rich pressure conditions. The superior catalytic properties of this particular cluster were attributed to the fast adsorption and dissociation of $\mathrm{O}_{2}$ on $\mathrm{Pd}_{6}{ }^{+}$ yielding the nano-oxide $\mathrm{Pd}_{6} \mathrm{O}_{4}^{+}$in conjunction with a comparably low $\mathrm{CO}$ bond strength to the palladium hexamer cluster. Furthermore, additional experiments utilizing the preoxidized cluster $\mathrm{Pd}_{6} \mathrm{O}^{+}$, as well as kinetic measurements, allowed an unambiguous determination of details of the catalytic reaction mechanism, revealing the nano-oxide $\mathrm{Pd}_{6} \mathrm{O}_{4}^{+}$as the catalytically active species. At temperatures below $190 \mathrm{~K}$ and under excess of $\mathrm{CO}$, the oxidation reaction of $\mathrm{CO}$ was observed to be impeded, and $\mathrm{CO}$ adsorption becomes the dominating process.

Complementary first-principles DFT computations of different possible reaction pathways allowed for molecular level insight into the energetics of the $\mathrm{CO}$ combustion reaction mediated by $\mathrm{Pd}_{6} \mathrm{O}_{4}{ }^{+}$. These studies revealed surprising similarities but also fundamental differences between the reaction mechanism and the energetics of the $\mathrm{CO}$ oxidation reaction mediated by the free palladium clusters and the reaction on $\operatorname{Pd}(111)$ single crystals. A major difference was identified to arise from a considerably reduced $\mathrm{CO}$ bond strength on $\mathrm{Pd}_{6}^{+}$compared to $\mathrm{Pd}(111)$, which protects the $\mathrm{Pd}_{6}^{+}$cluster against $\mathrm{CO}$ poisoning at room temperature and below, thus enabling effective low-temperature cluster-catalyzed $\mathrm{CO}$ oxidation.

The findings of the present study, employing gas-phase clusters as model systems, are found to be generally consistent with previous studies on Pd single-crystal surfaces as well as on supported nanoparticles and clusters, and hence, they serve to demonstrate the complementarity between the gas-phase cluster science approach and surface science studies. Furthermore, our investigation shows that size effects in the $\mathrm{O}_{2}$ and $\mathrm{CO}$ adsorption play an important role in this reaction in the case of small clusters. The observation of dramatic changes in the chemical and catalytic properties of small clusters by the mere addition or removal of one atom opens new possibilities for the rational design of effective low-temperature $\mathrm{CO}$ oxidation catalysts.

\section{ASSOCIATED CONTENT}

\section{S Supporting Information}

The following file is available free of charge on the ACS Publications website at DOI: $10.1021 / \operatorname{cs5016222.~}$

Experimental details, description of techniques, and supplemental data $(\underline{\mathrm{PDF}})$

\section{AUTHOR INFORMATION}

\section{Corresponding Authors}

*E-mail: thorsten.bernhardt@uni-ulm.de. Fax: (+49) 7315025452.

*E-mail: uzi.landman@physics.gatech.edu. Fax: (+1) 404-8947747.

\section{Notes}

The authors declare no competing financial interest.

\section{ACKNOWLEDGMENTS}

We gratefully acknowledge financial support by the Deutsche Forschungsgemeinschaft. In particular, S.M.L. is grateful to the European Social Fund Baden-Württemberg for a Margarete von Wrangell fellowship. The work of U.L. and R.N.B. at the
Georgia Institute of Technology was supported by a grant from the U.S. AFOSR, with partial support to U.L. by the Office of Basic Energy Sciences of the U.S. Department of Energy under Contract No. FG05-86ER45234. Calculations were performed at the Georgia Institute of Technology Center for Computational Materials Science.

\section{REFERENCES}

(1) Gates, B. C. Catalytic Chemistry; John Wiley \& Sons, Inc.: New York, Singapore, 1992.

(2) Handbook of Heterogeneous Catalysis; Ertl, G., Knözinger, E., Weitkamp, J., Eds.; Wiley-VCH: Weinheim, 1997; Vol. 4.

(3) (a) Conrad, H.; Ertl, G.; Küppers, J. Surf. Sci. 1978, 76, 323-342. (b) Engel, T.; Ertl, G. J. Chem. Phys. 1978, 69, 1267-1281.

(4) Szanyi, J.; Kuhn, W. K.; Goodman, D. W. J. Phys. Chem. 1994, 98, $2978-2981$

(5) (a) Nolan, P. D.; Lutz, B. R.; Tanaka, P. L.; Mullins, C. B. Surf. Sci. 1998, 419, L107-L113. (b) Guo, X.; Hoffman, A.; Yates, J. T., Jr. J. Chem. Phys. 1989, 90, 5787-5792.

(6) (a) Tracy, J. C.; Palmberg, P. W. J. Chem. Phys. 1969, 51, 48524862. (b) Ertl, G.; Koch, J. Z. Naturforsch. 1970, 25 a, 1906-1911. (c) Engel, T. J. Chem. Phys. 1978, 69, 373-385. (d) Bradshaw, A. M.; Hoffmann, F. M. Surf. Sci. 1978, 72, 513-535. (e) Behm, R. J.; Christmann, K.; Ertl, G.; Van Hove, M. A. J. Chem. Phys. 1980, 73, 2984-2995. (f) Duriez, C.; Henry, C. R.; Chapon, C. Surf. Sci. 1991, 253, 190-204. (g) Jones, I. Z.; Bennett, R. A.; Bowker, M. Surf. Sci. 1999, 439, 235-248. (h) Zorn, K.; Giorgio, S.; Halwax, E.; Henry, C. R.; Grönbeck, H.; Rupprechter, G. J. Phys. Chem. C 2011, 115, 11031111.

(7) Méndez, J.; Kim, S. H.; Cerdá, J.; Wintterlin, J.; Ertl, G. Phys. Rev. B 2005, 71, 085409.

(8) (a) Over, H.; Seitsonen, A. P. Science 2002, 297, 2003-2005. (b) Gabasch, H.; Knop-Gericke, A.; Schlögl, R; Borasio, M.; Weilach, C.; Rupprechter, G.; Penner, S.; Jenewein, B.; Hayek, K.; Klötzer, B. Phys. Chem. Chem. Phys. 2007, 9, 533-540.

(9) (a) Carlisle, C. I.; King, D. A.; Bocquet, M.-L.; Cerdá, J.; Sautet, P. Phys. Rev. Lett. 2000, 84, 3899-3902. (b) Lundgren, E.; Kresse, G.; Klein, C.; Borg, M.; Andersen, J. N.; De Santis, M.; Gauthier, Y.; Konvicka, C.; Schmid, M.; Varga, P. Phys. Rev. Lett. 2002, 88, 246103. (c) Li, W.-X.; Stampfl, C.; Scheffler, M. Phys. Rev. Lett. 2003, 90, 256102. (d) Reuter, K.; Scheffler, M. Appl. Phys. A: Mater. Sci. Process. 2004, 78, 793-798.

(10) Schmid, M.; Leonardelli, G.; Sporn, M.; Platzgummer, E.; Hebenstreit, W.; Pinczolits, M.; Varga, P. Phys. Rev. Lett. 1999, 82, $355-358$.

(11) Besenbacher, F.; Nørskov, J. K. Prog. Surf. Sci. 1993, 44, 5-66.

(12) (a) Surnev, S.; Kresse, G.; Ramsey, M. G.; Netzer, F. P. Phys. Rev. Lett. 2001, 87, 086102. (b) Dulub, O.; Hebenstreit, W.; Diebold, U. Phys. Rev. Lett. 2000, 84, 3646-3649.

(13) (a) Henry, C. R. Surf. Sci. Rep. 1998, 31, 231-325. (b) Goodman, D. W. Surf. Rev. Lett. 1995, 2, 9-24. (c) Nilius, N.; Risse, T.; Schauermann, S.; Shaikhutdinov, S.; Sterrer, M.; Freund, H.J. Top. Catal. 2011, 54, 4-12.

(14) (a) Meusel, I.; Hoffmann, J.; Hartmann, J.; Heemeier, M.; Bäumer, M.; Libuda, J.; Freund, H.-J. Catal. Lett. 2001, 71, 5-13. (b) Penner, S.; Bera, P.; Pedersen, S.; Ngo, L. T.; Harris, J. J. W.; Campbell, C. T. J. Phys. Chem. B 2006, 110, 24577-24584. (c) Shaikhutdinov, S.; Heemeier, M.; Hoffmann, J.; Meusel, I.; Richter, B.; Bäumer, M.; Kuhlenbeck, H.; Libuda, J.; Freund, H.-J.; Oldman, R.; Jackson, S. D.; Konvicka, C.; Schmid, M.; Varga, P. Surf. Sci. 2002, 501, 270-281. (d) Schalow, T.; Laurin, M.; Brandt, B.; Schauermann, S.; Guimond, B.; Kuhlenbeck, H.; Starr, D. E.; Shaikhutdinov, S. K.; Libuda, J.; Freund, H.-J. Angew. Chem., Int. Ed. 2005, 44, 7601-7605.

(15) Henry, C. R; Chapon, C.; Goyhenex, C. Surf. Sci. 1992, 272, 283-288.

(16) Stará, I.; Matolín, V. Surf. Sci. 1994, 313, 99-106. 
(17) Fischer-Wolfarth, J.-H.; Farmer, J. A.; Flores-Camacho, J. M.; Genest, A.; Yudanov, I. V.; Rösch, N.; Campbell, C. T.; Schauermann, S.; Freund, H.-J. Phys. Rev. B 2010, 81, 241416.

(18) Sitja, G.; Le Moal, S.; Marsault, M.; Hamm, G.; Leroy, F.; Henry, C. R. Nano Lett. 2013, 13, 1977-1982.

(19) Stará, I.; Nehasil, V.; Matolín, V. Surf. Sci. 1995, 331-333, 173177.

(20) (a) Landman, U. Solid State Commun. 1998, 107, 693-708. (b) Landman, U.; Barnett, R. N.; Moseler, M.; Yannouleas, C. In The Physics and Chemistry of Clusters, Proceedings of the Nobel Symposium 11; Campbell, E. E. B., Larsson, M., Eds.; World Scientific: Singapore, 2001; pp 42-68. (c) Landman, U. Proc. Nat. Acad. Sci. (USA) 2005, 102, 6671-6678. (d) Sanchez, A.; Abbet, S.; Heiz, U.; Schneider, W.D.; Häkkinen, H.; Barnett, R. N.; Landman, U. J. Phys. Chem. A 1999, 103, 9573-9578. (e) Landman, U.; Yoon, B.; Zhang, C.; Heiz, U.; Arenz, M. Top. Catal. 2007, 44, 145-158. (f) Bernhardt, T. M.; Heiz, U.; Landman, U. In Nanocatalysis; Heiz, U., Landman, U., Eds.; Springer-Verlag: Berlin, 2007; p 1-191;. (g) Lang, S. M.; Popolan, D. M.; Bernhardt, T. M. In Atomic Clusters: From Gas Phase to Deposited; Woodruff, P., Ed.; Elsevier: Amsterdam, 2007; Vol. 12, pp 53-90.

(21) (a) Abbet, S.; Heiz, U.; Häkkinen, H.; Landman, U. Phys. Rev. Lett. 2001, 86, 5950-5953. (b) Kunz, S.; Schweinberger, F. F.; Habibpour, V.; Röttgen, M.; Harding, C.; Arenz, M.; Heiz, U. J. Phys. Chem. C 2010, 114, 1651-1654. (c) Moseler, M.; Walter, M.; Yoon, B.; Landman, U.; Habibpour, V.; Harding, C.; Kunz, S.; Heiz, U. J. Am. Chem. Soc. 2012, 134, 7690-7699. (d) Yoon, B.; Landman, U.; Habibpour, V.; Harding, C.; Kunz, S.; Heiz, U.; Moseler, M.; Walter, M. J. Phys. Chem. C 2012, 116, 9594-9607.

(22) Mars, P.; van Krevelen, D. W. Chem. Eng. Sci. 1954, 3, 41-59. (23) (a) Kaden, W. E.; Wu, T.; Kunkel, W. A.; Anderson, S. L. Science 2009, 326, 826-829. (b) Kaden, W. E.; Kunkel, W. A.; Kane, M. D.; Roberts, F. S.; Anderson, S. L. J. Am. Chem. Soc. 2010, 132, 1309713099.

(24) Wu, T.; Kaden, W. E.; Kunkel, W. A.; Anderson, S. L. Surf. Sci. 2009, 603, 2764-2770.

(25) Robles, R; Khanna, S. N. Phys. Rev. B 2010, 82, 085428.

(26) Huber, B.; Koskinen, P.; Häkkinen, H.; Moseler, M. Nat. Mater. 2006, 5, 44-47.

(27) Reilly, N. M.; Johnson, G. E.; Castleman Jr., A. W. In Model systems in catalysis: Single crystals to supported enzyme mimics; Rioux, R. M., Ed.; Springer Science + Business Media: New York, 2010.

(28) Böhme, D. K.; Schwarz, H. Angew. Chem., Int. Ed. 2005, 44, 2336-2354.

(29) Lang, S. M.; Bernhardt, T. M. Phys. Chem. Chem. Phys. 2012, 14, 9255-9269.

(30) (a) Hintz, P. A.; Ervin, K. M. J. Chem. Phys. 1995, 103, 78977906. (b) von Gynz-Rekowski, F.; Ganteför, G.; Kim, D. Y. Eur. Phys. J. $D$ 2007, 43, 81-84.

(31) (a) Bare, W. D.; Citra, A.; Chertihin, G. V.; Andrews, L. J. Phys. Chem. A 1999, 103, 5456-5462. (b) Huber, H.; Klotzbücher, W.; Ozin, G. A.; Voet, A. V. Can. J. Chem. 1973, 2722-2736. (c) Andersson, M.; Rosén, A. J. Phys.: Condens. Matter 2010, 22, 334223.

(32) Ramond, T. M.; Davico, G. E.; Hellberg, F.; Svedberg, F.; Salén, P.; Söderqvist, P.; Lineberger, W. C. J. Mol. Spectrosc. 2002, 216, 1-14.

(33) (a) Huber, B.; Häkkinen, H.; Landman, U.; Moseler, M. Comput. Mater. Sci. 2006, 35, 371-374. (b) Roques, J.; LacazeDufaure, C.; Mijoule, C. J. Chem. Theory Comput. 2007, 3, 878-884.

(c) Wan, X.; Yoshizawa, K.; Ohashi, N.; Endou, A.; Takami, S.; Kubo, M.; Miyamoto, A.; Imamura, A. Scripta mater. 2001, 44, 1919-1923.

(d) Kalita, B.; Deka, R. C. J. Am. Chem. Soc. 2009, 131, 13252-13254.

(34) Chen, Y.-M.; Armentrout, P. B. J. Chem. Phys. 1995, 103, 618625.

(35) (a) Lang, S. M.; Fleischer, I.; Bernhardt, T. M.; Barnett, R. N.; Landman, U. J. Am. Chem. Soc. 2012, 134, 20654-20659. (b) Lang, S. M.; Frank, A.; Fleischer, I.; Bernhardt, T. M. Eur. Phys. J. D 2013, 67, 19.

(36) Lang, S. M.; Fleischer, I.; Bernhardt, T. M.; Barnett, R. N.; Landman, U. J. Phys. Chem. A 2014, 118, 8572-8582.
(37) (a) Spasov, V. A.; Ervin, K. M. J. Chem. Phys. 1998, 109, 53445350. (b) Hintz, P. A.; Ervin, K. M. J. Chem. Phys. 1994, 100, 57155725. (c) Gruene, P.; Fielicke, A.; Meijer, G.; Rayner, D. M. Phys. Chem. Chem. Phys. 2008, 10, 6144-6149.

(38) Cox, D. M.; Reichmann, K. C.; Trevor, D. J.; Kaldor, A. J. Chem. Phys. 1988, 88, 111-119.

(39) Lang, S. M.; Schnabel, T.; Bernhardt, T. M. Phys. Chem. Chem. Phys. 2012, 14, 9364-9370.

(40) (a) Blomberg, M. R. A.; Lebrilla, C. B.; Siegahn, P. E. M. Chem. Phys. Lett. 1988, 150, 522-528. (b) Goursot, A.; Papai, I.; Salahub, D. R. J. Am. Chem. Soc. 1992, 114, 7452-7458. (c) Schultz, N. E.; Gherman, B. F.; Cramer, C. J.; Truhlar, D. G. J. Phys. Chem. B 2006, 110, 24030-24046. (d) Pacchioni, G.; Chung, S.-C.; Krüger, S.; Rösch, N. Surf. Sci. 1997, 392, 173-184. (e) Pacchioni, G.; Koutecký, J. J. Phys. Chem. 1987, 91, 2658-2664. (f) Andzelm, J.; Salahub, D. Int. J. Quantum Chem. 1986, 29, 1091-1104. (g) Zanti, G.; Peeters, D. Eur. J. Inorg. Chem. 2009, 3904-3911. (h) Kalita, B.; Deka, R. C. Eur. Phys. J. D 2009, 53, 51-58.

(41) Reber, A. C.; Khanna, S. N.; Tyo, E. C.; Harmon, C. L.; Castleman, A. W., Jr. J. Chem. Phys. 2011, 135, 234303.

(42) Bernhardt, T. M. Int. J. Mass Spectrom. 2005, 243, 1-29.

(43) Keller, R.; Nöhmeier, F.; Spädtke, P.; Schönenberg, M. H. Vacuum 1984, 34, 31-35.

(44) Schumacher, E. DETMECH - Chemical Reaction Kinetics Software; University of Bern: Chemistry Department, 2003.

(45) (a) Steinfeld, J. I.; Francisco, J. S.; Hase, W. L. Chemical Kinetics and Dynamics; 2nd ed.; Prentice Hall: Upper Saddle River, NJ, 1999. (b) Laidler, K. J. Chemical Kinetics, 3rd ed.; HarperCollins: New York, 1987.

(46) Bernhardt, T. M.; Hagen, J.; Lang, S. M.; Popolan, D. M.; Socaciu-Siebert, L.; Wöste, L. J. Phys. Chem. A 2009, 113, 2724-2733.

(47) Langevin, P. M. Ann. Chim. Phys. 1905, 5, 245-288.

(48) Barnett, R. N.; Landman, U. Phys. Rev. B 1993, 48, 2081-2097.

(49) Troullier, N.; Martins, J. L. Phys. Rev. B 1991, 43, 1993-2006.

(50) Perdew, J. P.; Burke, K.; Ernzerhof, M. Phys. Rev. Lett. 1996, 77, $3865-3868$.

(51) (a) Moseler, M.; Häkkinen, H.; Barnett, R. N.; Landman, U. Phys. Rev. Lett. 2001, 86, 2545-2548. (b) Moseler, M.; Häkkinen, H.; Landman, U. Phys. Rev. Lett. 2002, 89, 176103.

(52) (a) Marcus, R. A. J. Chem. Phys. 1952, 20, 359-364. (b) Holbrook, K. A.; Pilling, M. J.; Robertson, S. H. Unimolecular Reactions, 2nd ed.; John Wiley \& Sons Ltd.: Chichester, 1996.

(53) (a) Shi, Y.; Ervin, K. M. J. Chem. Phys. 1998, 108, 1757-1760. (b) Balaj, O. P.; Balteanu, I.; Roßteuscher, T. T. J.; Beyer, M. K.; Bondybey, V. E. Angew. Chem., Int. Ed. 2004, 43, 6519-6522. (c) Socaciu, L. D.; Hagen, J.; Bernhardt, T. M.; Wöste, L.; Heiz, U.; Häkkinen, H.; Landman, U. J. Am. Chem. Soc. 2003, 125, 1043710445. (d) Wallace, W. T.; Whetten, R. L. J. Am. Chem. Soc. 2002, 124, $7499-7505$.

(54) Zheng, G.; Altman, E. I. J. Phys. Chem. B 2002, 106, 1048-1057.

(55) Engel, T.; Ertl, G. In The Chemical Physics of Solid Surfaces and Heterogeneous Catalysis; King, D. A., Woodruff, D. P., Eds.; Elsevier: Amsterdam, 1982; Vol. 4, pp 73-93.

(56) Conrad, H.; Ertl, G.; Küppers, J.; Latta, E. E. Surf. Sci. 1977, 65, $245-260$.

(57) Farkas, A. P.; Diemant, T.; Bansmann, J.; Behm, R. J. ChemPhysChem 2012, 13, 3516-3525.

(58) (a) Matsushima, T.; Asada, H. J. Chem. Phys. 1986, 85, 16581668. (b) Kim, S. H.; Méndez, J.; Wintterlin, J.; Ertl, G. Phys. Rev. B 2005, 72, 155414. 